\title{
Prosthetic Aortic Heart Valves
}

\author{
Hadi Mohammadi ${ }^{1,2,3, *}$ and Guy Fradet ${ }^{1,2}$
}

*Correspondence: hadi.mohammadi@ubc.ca

${ }^{1}$ The Heart Valve Performance Laboratory, School of Engineering, Faculty of Applied Science, University of British Columbia, Kelowna, BC, Canada.

2Department of Surgery, Faculty of Medicine, University of British Columbia, Vancouver, BC, Canada.

${ }^{3}$ Biomedical Engineering Graduate Program, Faculty of Applied Science, University of British Columbia, Vancouver, BC, Canada.

\begin{abstract}
In this review, the anatomy and structure of the aortic valve and its prostheses are comprehensively discussed. Cardiac anatomy and function, human heart valves and their prostheses are also extensively discussed. The current status of prosthetic heart valves along with the next generation of these devices is broadly deliberated. Ather promising options such astranscatheter technologies (percutaneous valves), minimally invasive techniques, and the construction of prosthetic valves using tissue engineering as futureristic areas of research are brought into conclusion.

Keywords: Aortic Valve, Prosthetic Valve, Mechanical Heart Valves, Bioprostheic Valves, Hydrogel Biomaterials, Surgical Tools
\end{abstract}

\section{Background}

\section{Cardiac Anatomy and Function}

The heart is undoubtedly one of the most dynamic organs in the human body. The main function of the human heart is to circulate the blood, acting as a synchronized reciprocating double-pump. In every heartbeat, blood is squeezed into the arteries from the heart, and then returns back to the heart in a one-way circuit through the veins. The delivery of the oxygen and nutrients takes place in the connection between arteries and veins, known as the capillary network, which are known as micro vessels $[\mathbf{1}, \mathbf{2}]$. Blood flows through the circulation system due to the continuous rhythmic heart muscle contractions. However, the form, function and complexity of the heart arenot the same in different animals. In some animals it is similar to a beating tube as observed in fish, spiders and worms.In some other animals, it may have a more complex structure as observed in birds and reptiles. In humans and pigs, the heart is much more developed as asignificant evolution from a single to a double pump is observed. It should be noted that the pig heart is the closest to the human heart in shape, function and complexity [1].

In general, the heart is made of active muscles known as myocardium and is as big as a closed fist (Figure 1). The average dimensions of an adult heart are $130 \times 95 \times 65 \mathrm{~mm}^{3}$ with a weight of $300 \mathrm{~g}$. It is a somewhat conic structure, with the wide base oriented towards the right and the head, the apex oriented downwardsto the left. It sits between the lungs and behind the ribcage for safety and protection. The cavity in which the heart is locatedis known as the thoracic cavity, which is behind the breastbone, also known as the sternum, in front of trachea and esophagus, and above the diaphragm [3]. The diaphragm is a curved-shaped membrane made of muscle that is located between the chest and the abdomen as a separator. Since it is placed in the thoracic cavity, it also has another name which is the thoracic diaphragm. The main axis of the heart is aligned along the body's midline, while the apex is inclined slightly towards the left side. Due to the inclination of the heart towards the left, about $\% 65$ of its mass is on the left side of the body while the remaining $\% 35$ is on the right side [4].

A thin layer of tissue, known as the pericardium, covers the outside of the myocardium. Pericardium is a strong two-layered membrane that shields the heart. There are two sub-layers in the pericardial membrane: the outermost fibrous pericardium and the inner serous pericardium. The serous pericardium, is further separated into two sub-layers: the parietal pericardium, which is connected to and inseparable from the fibrous pericardium, and the visceral pericardium, which is a segment of the epicardium. The epicardium is the layer directly outside of the myocardium. The heart is not attached to any other organs and issuspended in the pericardium. The firm outer segment of the sac, or fibrous pericardium, is strongly connected to the diaphragm under the mediastinal pleura on the side and the 


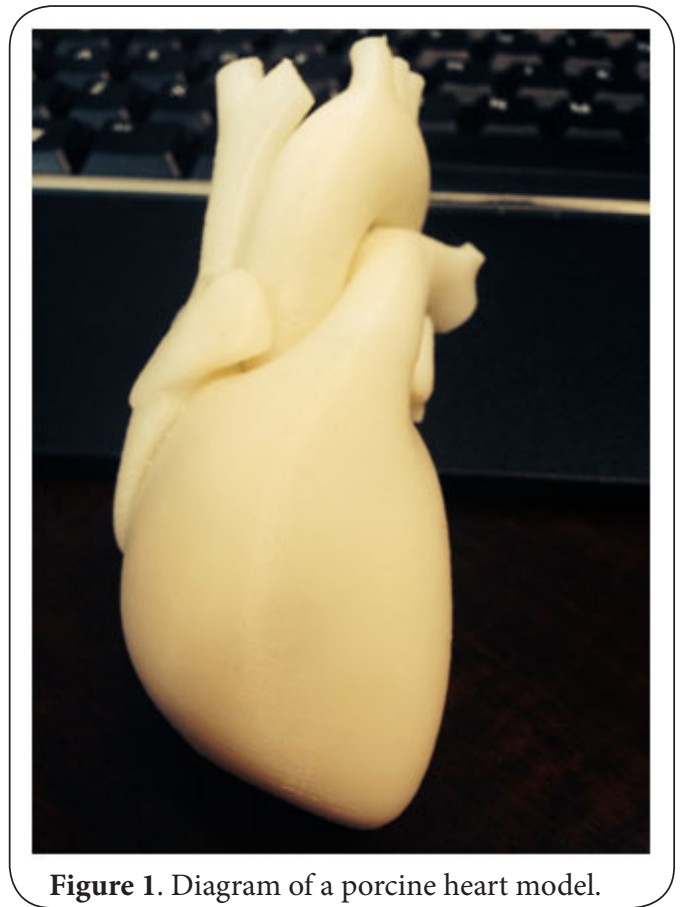

sternum in front [5]. It progressively becomes the coatings of the superior vena cava and the pulmonary arteries and veins. The serous membrane lines the fibrous pericardium and covers the heart wall. The segment of membrane lining the fibrous pericardium is known as the parietal serous layer or parietal pericardium, and the segment coating the heart is known asthe visceral serous layer, visceral pericardium or epicardium. There is a gap between these two layers of serous membrane known as the precardial cavity. This cavity is filled by 10 to $15 \mathrm{ml}$ of pericardial fluid, which is secreted by the serous membranes. The pericardial fluid is responsible for the lubrication of the two membranes during the cardiac cycle so that the energy loss due tofriction is almost zero [6].

The human heart has four chambers (or cavities) known as ventricles (bottom chambers) and atria (top chambers). Blood flows from all regions of the body intothe vena cava vein, which empties into the right atrium that collects all of the deoxygenated blood. The inferior vena cava is responsible for collecting deoxygenated blood from the lower body, including the legs, back, abdomen and pelvis.The superior vena cava is responsible for collecting deoxygenated blood from the upper body, including the brain, neck, arms, and chest. All of the collected blood in the right atrium then goes directly to the right ventricle, whichpumps it to the main pulmonary artery and subsequently the lungs. This is where the blood receives fresh oxygen and releases its carbon dioxide [3]. The power needed to pump the deoxygenated blood to the lung is considerably less than that required for systemic circulation. The pulmonary veins connect the lungs to the left atrium and bring oxygenated blood from the lungs back to the left atrium. In fact, the pulmonary veins are the only veins in the body that carry oxygen-rich blood. All of the collected blood in the left atrium then goes directly to the left ventricle [4]. The left ventricle then pumps it to the systemic circulation system through the aorta to deliver oxygen to the remainder of the body. It should be noted that in the right half of the heart, the wall is thinner and the heart valves have lessconcentration and density of collagen fibers whencompared to the left side. It is observed that these two pumps (halves), which are completely separate, work simultaneously together in a very effective way. In fact, each pump is responsible for driving the blood into a distinct circuit, either the pulmonary circuit or the systemic circuit. The pulmonary circulation is the circuit by which blood is oxygenated and requires a much lower driving force than the systemic circulation. This is mainly because of the much lower resistance between the blood and vessels. Thisalsoexplains why the left part of the heart has a stronger and thicker structure than the right side, and why the blood pressure at the onset of the systemic circuitis much higher than that of the pulmonary circuit (Figure 2) [6].

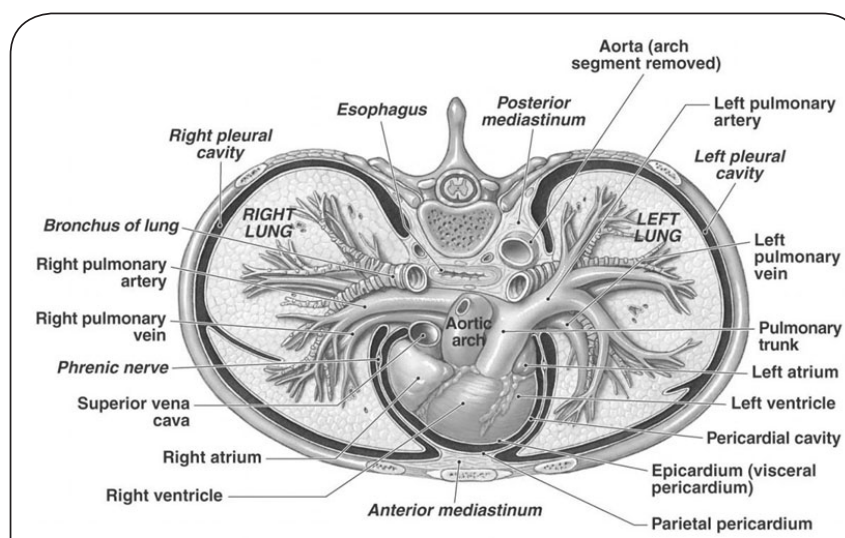

Figure 2. The horizontal section of the heart [7].

The heart wall is composed of three identifiable layers, the epicardium, the myocardium, and the endocardium. Coronary arteries and veins are imbedded within the epicardium and the myocardium. The epicardium (or visceral pericardium) is made of a surface of compacted epithelial cells covering the connective tissues. The myocardial layer is made of the contractile bundles of striated muscle fibres. These bundles are constructed in a branching-like pattern and cause a wringingmovement thatproficiently squeeze the heart champers on each cardiac cycle. The thickness of the myocardium is not constant and highly depends on the pressure required to move the blood in each cardiac chamber. Also, the atrial walls are much thinner when compared to the ventricular walls. The myocardium is made of muscle fibres which are then broken down into smaller structurescalled cardiac muscle cells. Each cardiac muscle cell is then subdivided into smaller structures known as myofibrils. Myofibrils are made of smaller unites known as sarcomeres. A sarcomere is the 
fundamental unit of cardiac muscle and is highly responsible for the contractibility of cardiac muscle [8]. The length of sarcomeres is approximately a few microns and theyhave very complicated structures. The cardiac sarcomere is an extremely organized cytoskeletal structure made mainly of myosin, actin and a set of regulatory giant proteins known as titin. Myosin is known to be the cytoskeletal motor protein in the muscle cell thatis directly accountable for converting chemical energy (ATP) into mechanical force and eventually muscle contraction. Myosin is the thick filament while actin is called the thin filament. Myosinbinds to actin through its long, fibrous tail and a globular head. Its globular head is also attached to ATP, which is the main provider of energy for muscle activities. Actin molecules are attached to the $Z$ line, which are limits of the sarcomere unit andmyosin is attached to the $Z$ line through titin. The space in which titin is located is called the I-band and the space between the two actin filaments in a sarcomere is called $\mathrm{H}$ zone (Figure 3) [8].

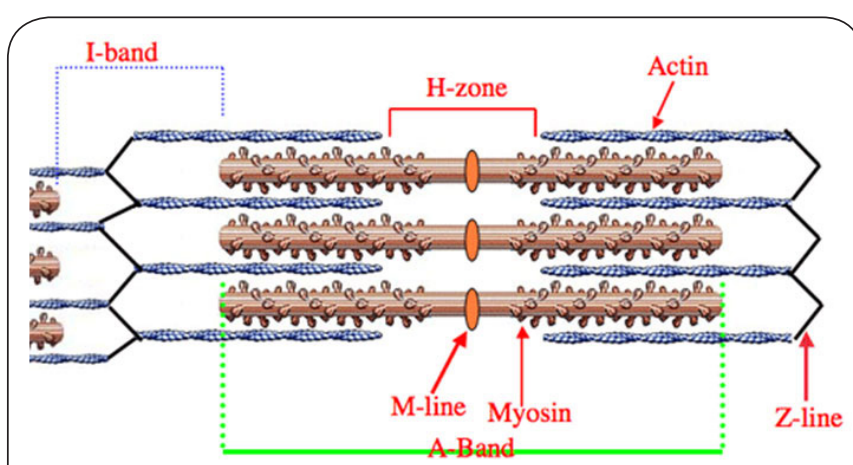

Figure 3. Structure of a sarcomere.

Cardiac muscle and skeletal muscles have similar properties. The heart containspacemaker cells that generate the depolarization and action potentials to cause cardiac cells to contract. Regularheart contraction is self-driven,which is not based on neuron stimulations. Cardiac muscle cells are positioned next to each other with gap junctions in between. This allows action potentials to quickly spread from one cell to another to connect all the cardiac cells in a very organized way. Another role of gap junctions is to let the sinoatrial node cells generate the action potential, which is communicated via the gap junctions throughout the heart. This helps heart contract and relax in a very controlled way $[6,8]$. Cardiac muscle cells in atria and ventricles are different. Some are called the pacemaker cells, which are in the sinoatrial node, and some are called the atrial and ventricular cells that cause the contraction only. Nevertheless, all share the same mechanisms of excitation-contraction coupling; however, there are certain features thatdistinguish the sinoatrial cells [9].

The muscle contraction mechanism leads to a beating heart. Regular heartbeat is a self-driven mechanism that is completely due to the inherent rhythmicity of cardiac muscle.
In normal conditions, there is absolutely no contribution from the neural system or any external regulatory mechanisms to stimulate the regular cardiac muscle. In fact, the root of this rhythmic mechanism is in the cardiac muscle. Thisoriginates during the cardiac development in the embryo long before various levels of the neural systemhave developed. Each subsegment of the heart structure has the beating property where small cardio-myofibril in a tissue culture continuously contract rhythmically. It should be noted that the regular contraction in cardio-myofibrils is either maximum (100\% contraction) or nothing( $0 \%$ contraction), unlike skeletal muscle cells. This strongly indicatesthe lack of neural network contribution to the regular heart construction. If more or less blood is required to be circulated through the body (depending on the physical or mental conditions), the heart rate needs to increase or decrease [10]. The regulation of heart rate is directlycontrolled by the neural network, which is achieved specifically by the sympathetic nerves and the parasympathetic fibres in the vagus nerve. The sympathetic nerves serve as a cardiac accelerator and the parasympathetic nerves act as a cardiac decelerator. If the vagus nerve is stimulated, it reduces the heart rate [11]. Consequently, the atrial contractility is also reduced and the cardiac output is decreased. If parasympathetic nerves are stimulated, the contractility of the atria and ventricles as well asheart rate is increased. The effect of the sympathetic and parasympathetic nerves is similar to an analog system, meaning that the heart rate (or cardiac muscle contraction) highly depends on the degree of stimulation. The period of one full contraction and relaxation of the heart is defined as the cardiac cycle, which includes the relaxation phase (diastole) and the contraction phase (systole). The pressure developed at the beginning of the systemic circulation varies during these two periods. The normal diastolic pressure is between 60 to $80 \mathrm{mmHg}$ and the normal systolic pressure is between 90 to $120 \mathrm{mmHg}$ [12].

The systole phase normally takes between 0.3 to 0.4 seconds, in which $80 \mathrm{cc}$ to $100 \mathrm{cc}$ is pumped to the systemic and the pulmonary circulation systems together. In the beginning of this phase, the systemic blood pressure is maximum with a value of 90 to $120 \mathrm{mmHg}$. The ventricle pressure is slightly higher due to: (1) the pressure drop through the aortic valve, and (2) the compliance of the aortic root. In fact, atrial systole follows at the end of ventricular diastole in which the ventricles are relaxed and filled for the next cardiac cycle. In the beginning of the cardiac cycle, both atria and ventricles are in the diastolic phase [13]. There is a period of quick relaxation of the ventricles followed by a quick atrial systole. Simultaneously, the arterial blood pressure falls to its minimum, known as the diastolic blood pressure (approximately $80 \mathrm{mmHg}$ ). Ventricular relaxation again takes place after the blood has been pumped during ventricular systole out of the heart.

The heart myocardium is known to be active as there are electrical stimulations which cause the myocardial tissue to contract. The key factor for the heart to act like a pump is 
Mohammadi et al. Cardiovascular System 2017,

http://www.hoajonline.com/journals/pdf/2052-4358-5-2.pdf

doi: $10.7243 / 2052-4358-5-2$

the myocardial contraction and relaxation. The contraction of myocardium causes a high pressure in each chamber and the relaxation causes the pressure to drop. The periods of relaxation and contraction are called diastole and systole, respectively. These electrical stimulations are initiated in the sinoatrial (SA) node, which is locatedin the right atrium wall. Through an impulse started from the SA node and then propagated in the entire atrium wall, the two atria contract. There is another node in the ventricle chambers where electrical impulses initiate, causing them to contract. This node is known as the atrioventricular (AV) node, which is locatedat the interface of the two atria. The period of diastole is longer than that of systole, which is the time for heart to relax between two consecutive contractions. A healthy human heart beats around 100,000 times every day, almost 70 beats per minute. The total amountof blood pumped by an adult heart every day is about 7,500 liters [14].

One of the main features of the cardiovascular system through which the performance of the heart is evaluated is the cardiac output. Cardiac output is the amount of blood pumped by the two ventricular chambers. It is typically considered as the volume of blood per minute or litres of blood per minute. If the stroke volume,also known as the heart output, in each cardiac cycle is multiplied by the number of beats per minute (heart rate), the cardiac output can be calculated $[10,12]$. It should be noted that the levelof cardiac output is directly proportional to the entire body's need for oxygen and other nutrients. In normal conditions, the cardiac output at rest (or sleeping) is evaluated to be approximately 5 litres per minute. It is typically increased upon the initiation of any types of physical or mental activities by $50 \%$ to $500 \%$, depending on the person [15].

\section{Coronary Arteries}

The mechanism by which oxygen and nutrientsare delivered to the heart is, somewhat surprisingly, not by diffusion. It is actually achieved though the coronary artery vascular network. This network consists of two main coronary arteries, known as the right and the left coronary artery. Generally, the left coronary artery has a Y-shape structure, and it branches to two major smaller arteries. These are called the left anterior descending and the circumflex coronary arteries. The left anterior descending and the circumflex coronary arteries are divided to many smaller arteries that cover the entire cardiac surface [17].

The right and left coronary arteries originate from the aortic root, or more specifically, from the right and left aortic sinuses. These are better known as the right coronary sinus and the left coronary sinus, respectively. The other aortic sinus is called the non-coronary sinus of Valsalva, simply because there is no coronary artery that originates from there. The left coronary arterial system is said to be more vital than the right arterial system, simply because it covers a larger area. This explains why the size of the main left coronary artery is larger than that of the right coronary artery (Figure 4) $[15,18]$. The lumen diameter of the main branch of the right coronary artery is approximately $2.5 \mathrm{~mm}$. The areas covered by the right coronary artery system are as follows: the right ventricular outflow area, the atrioventricular node, the sinoatrial node, and

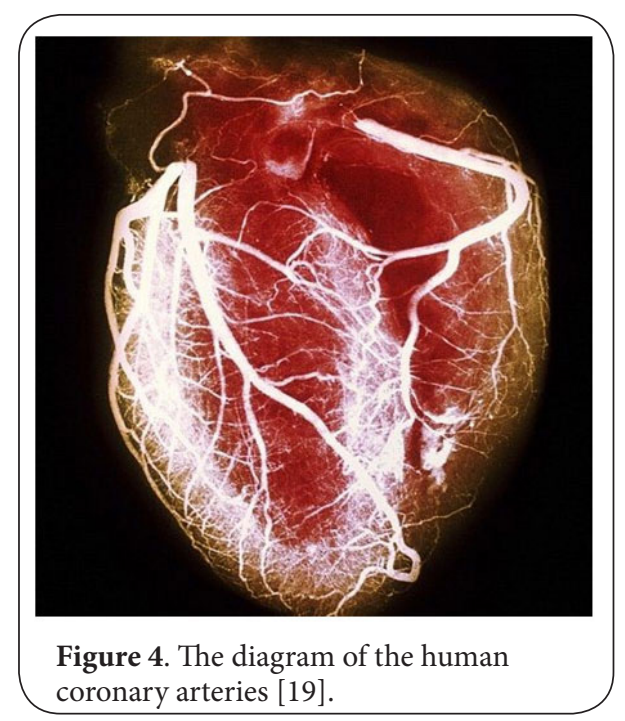

the bulk of the right ventricle. Also, the right coronary artery has branches that spread into the interventricular septum and merge with arteriolar branches from the left coronary artery at the border of the two ventricles. The lumen diameter of the main branch of the left coronary artery is approximately 3.5 $\mathrm{mm}$ with a length between $10 \mathrm{~mm}$ and $20 \mathrm{~mm}[12,20]$. The subdivisions of the main left coronary are two smaller arteries, called the anterior descending and the circumflex arteries. The areas covered by the left coronary artery are mainly the left ventricle and the interventricular septum [15-21]. The left circumflex artery is positioned along the atrioventricular groove, which is then divided into an arterialand the obtuse marginal branch. The arterial branch is then connected to the sinoatrial node and the obtuse marginal branch covers the posterior left ventricular wall towards the apex. It should be noted that veins usually follow the same pattern as the distribution of the distal arteries [22].

\section{Review}

\section{Human Heart Valves}

To regulate the precise blood flow within the heart, there are four unidirectional valves in the heart. These valves are categorized as:(1) the atrioventricular valves or tricuspid and mitral valves, and (2) the semilunar valves or pulmonary and aortic valves. The atrioventricular valves are known to have very thin structures thatare positioned between the atria and the ventricles. The right atrioventricular valve is called the tricuspid valve because of its three unequally shaped leaflets. The leaflets are covered by the endocardium and are strength- 
ened with a layer of compact connective tissue. The chordae tendineae which is a connective tissue (similar to a tendon)is coated by endocardium and connects the papillary muscles and the ventricular surface of the middle layer of each cusp. The left atrioventricular orifice is the location of the mitral valve. The mitral valve is connected in the same way as the tricuspid, but it has a stronger and thicker structure because the operational pressure around the mitral valve is much higher. First, blood is pumped through the tricuspid and mitral valves as the atria contract. Following the ventricle contraction, blood is pushed backward, flowing between the flaps and walls of the ventricles [20-23]. The flaps are consequently pushed upward sothat the valvesare closed completely. In this case, a complete separator is formed between the atria and the ventricles. The motion of the leaflets is controlled by the chordae tendineae and papillary muscles so as to prevent the leaflets from opening into the atria. The semilunar valves, known as the pulmonary and aortic valves, are pocket-like structures positioned where the pulmonary artery and the aorta are connected to the ventricles. The pulmonary valve is positionedat the orifice between the right ventricle and the pulmonary artery. The aortic valve is positioned between the left ventricle and aorta. The three leaflets of the pulmonary valves arethinner than that of the aortic valve, but in both valves there is no connective tissue of chordae tendineae. Due to this, the motion of the leaflets isnot restricted by any cords during the opening and closing phases. The closing phase of the heart valves is associated with an audible sound, known as the heartbeat. The first sound is because of the closure of the mitral and tricuspid valves, and the second one is when the pulmonary and aortic valves close [18-22].

The following diagram (Figure 5) shows the four cardiac

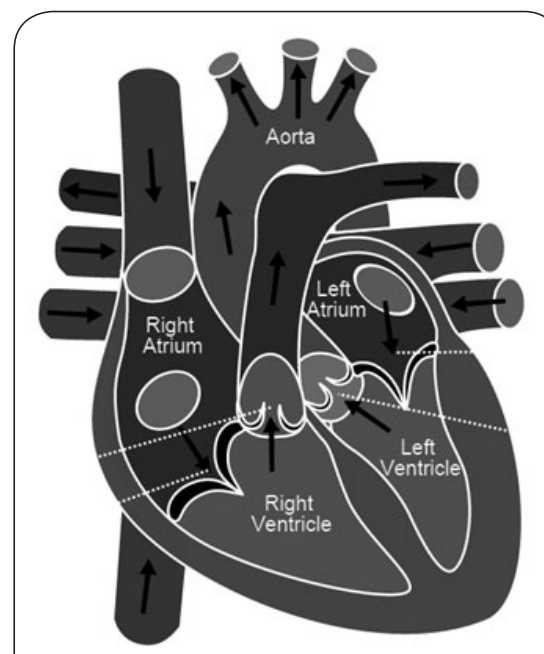

Figure 5. The structure of heart and heart valves, four chambers (atriums and ventricles) and four heart valves: pulmonary valve, mitral valve, aortic valve and tricuspid valve are shown clearly [26]. valves and how they are positioned and oriented within the heart. In a healthy human heart, the location and orientation of the valves is much more complicated, but the following diagram makes it easier to understand. The cardiac valves are positioned in between the chambers of the heart and at the onset of the aorta and pulmonary artery. The role of valves is acritical component inproviding the proper direction for the flow of blood through the heart and thereafter. All of the valves, in normal physiological condition, perform as unidirectional check-valves thatallow blood to flow in only one direction (i.e., from one chamber to another, or letting blood flow to the lungs or to the systemic circulation of body in only one direction) [24]. The valves control the direction and the rate of the blood flow through the heart in a timely manner by opening and closing the leaflets during diastolic and systolic phases. The mechanism by which valves open and close during the cardiac cycle is known to be almost passive as the pressure gradient before and after the valves is the driving force. This pressure gradient is generated within the heart and highly depends on the compliance of the heart and arteries [10-25]. However, in the mitral valve, the opening and closing phases are not completely passive as the papillary muscles and the chordae tendineaelocated within the left ventricle partly contribute, as mentioned before.

In summary, the four heart valves are known as: (1) the tricuspid valve, (2) the pulmonary valve, (3) the mitral valve, and (4) the aortic valve.

- Tricuspid valve: located between the right atrium and the right ventricle

- Pulmonary valve: located between the right ventricle and the pulmonary artery

- Mitral valve: located between the left atrium and the left ventricle

- Aortic valve: located between the left ventricle and the aorta

As the heart muscle contracts and relaxes, the valves open and close, letting blood flow into the ventricles and atria at alternate times.As to the stages ofhow the valves function normally in the left ventricle: (1) after the left ventricle contracts, the aortic valve closes and the mitral valve opens. This allows blood flow from the left atrium into the left ventricle, (2) once the left atrium contracts, more blood flows into the left ventricle, and (3) when the left ventricle contracts again, the mitral valve closes and the aortic valve opens, and blood flows into the aorta [24-27].

The aortic valve, located at the onset of the aorta, is the portion of the aortic root thatconnects the heart to the systemic circulation of the body. It plays a key role in the function of the heart and the cardiovascular system. It also preserves optimal coronary perfusion and plays a significant role in providing a non-turbulent flow in the vascular system. Each component of the aortic root has its own individual histological features and anatomical construction. The specific shape of the annulus, including the three aortic sinuses' interleaflet triangles, 
Mohammadi et al. Cardiovascular System 2017,

the sinotubular junction, commissures, and the aortic valve leaflet tissue interrelate with each other in a very precise way in order to preserve ideal function. This harmonized active behaviour has been demonstrated to be significantfor coronary perfusion, especific flow characteristics, and left ventricular function [28].

\section{Annulus}

The aortic valve cusps are connected to the sinuses' wall by a very solid collagenous network known asthe annulus. The word annulus indicates a circular structure of the aortic ring which is not accurate. In fact, the only circular component of the aortic root is the region where the left ventricle and the fibroelastic wall of the arterial trunk intersect. The annulus has a crown-like shape thatis located on the interface of the left ventricle and the aortic root. It is made up of a fibrous structure thatis strongly connected to the media of the aortic sinuses distally and also to the muscular and the membranous septa anteriorly and proximally. The three superior portions of the annulus are known as commissures.In the non-coronary sinus of the annulus, there are regions in which no myocardial muscle exists and instead havea cartilaginous structure. These regions are the locations where the layers of the cusps exhibit a specific arrangement. The ventricular and arterial layers become separate, and the middle collagenous layer exhibits a cuneiform structure. The ventricular layer blends into the endocardial layer gradually and the arterial layer blends to the sinus wall. Small arteries and veins are positioned in the connective tissue layer [29-34]. Elastic and collagen fibers as well asneuronal structures are present in the annulus.

\section{Commissures}

The apex of annulus in the region where the lannula of two cusps are connected to the aortic wall. This occurs at the height of the sinotubular junction and is known as a commissure. In this region, two cusps are attached to the aortic wall in parallel for a short distance, which makes three commissures. The first one is formed by the right- and left-coronary cusps and is oriented anteriorly. Itis relatively opposite to the equivalent commissure of the pulmonary valve. The second one is formed by the right and non-coronary cusps and is on the right anterior. Finally, the third one is formed by the left- and non-coronary cusps, typically on the right posterior aspect of the aortic root. The commissures are made up of fibres and structurally support the valve cusps. They arepositioned above three triangular regions known as the interleaflet triangles [35].

The pressure load on the leaflets is transferred to the annulus, mostly by a network of collagen fibers in the closing phase. The majority of these fibers appear to originate at the commissure level. The collagen fibers of the middle layer are positioned inthe radial direction in the region close to the commissures. At one end, these fibers penetrate to the intima layer of the aortic root and atthe other end, they blend to the media layer in which they are fixed. This particular microstructure provides an ideal transferal of force from the leaflet tissue to the base (attachment) and eventually, to the aortic wall [35-36].

\section{Interleaflet Triangles}

These interleaflet triangles are basically the three regions between the apex of the crown-like annulus and the anatomic boundary. In fact, the interleaflet triangles and the ventricular outflow area are on the same extension and the sinotubular junction in the region of the commissures and interleaflet triangles are at the same level. The triangle formed by the right- and the left-coronary sinuses is positioned towards the pulmonary valve, whose base is located on the septal section of the right ventricular outflow area. Attachment to the pulmonary artery is attained in almost half of cases by the ligament of the infundibulum. The triangle formed by the right- and non-coronary sinuses is positioned towards the right atrium and is in direct connection with the membranous septum. The close communication between the conduction system and the aortic root occurs in this region. Lastly, the triangle formed by the left- and non-coronary sinuses is in direct connection inferiorly with the aortic or anterior cusp of the mitral valve. These three triangles separate and indicate the three sinuses in the healthy valve (Figure 6) [34-40].

The three intraleaflet triangles are attached by a delicate fibrous membrane of the aorta between the extended sinuses. The triangle formed by the left-coronary and non-coronary sinus becomes a portion of the aortic-mitral valvular curtain. Its structure is mainly fibrous tissue, which is similar to the mitral valve cusp structure. The triangle formed by the noncoronary and the right-coronary aortic sinus is merged in the membranous portion of the septum and is made up of fibrous tissue. However, the triangle formed by the right-coronary and left-coronary sinus in the region of the subpulmonary infundibulum is different. This triangle is mainly reinforced by

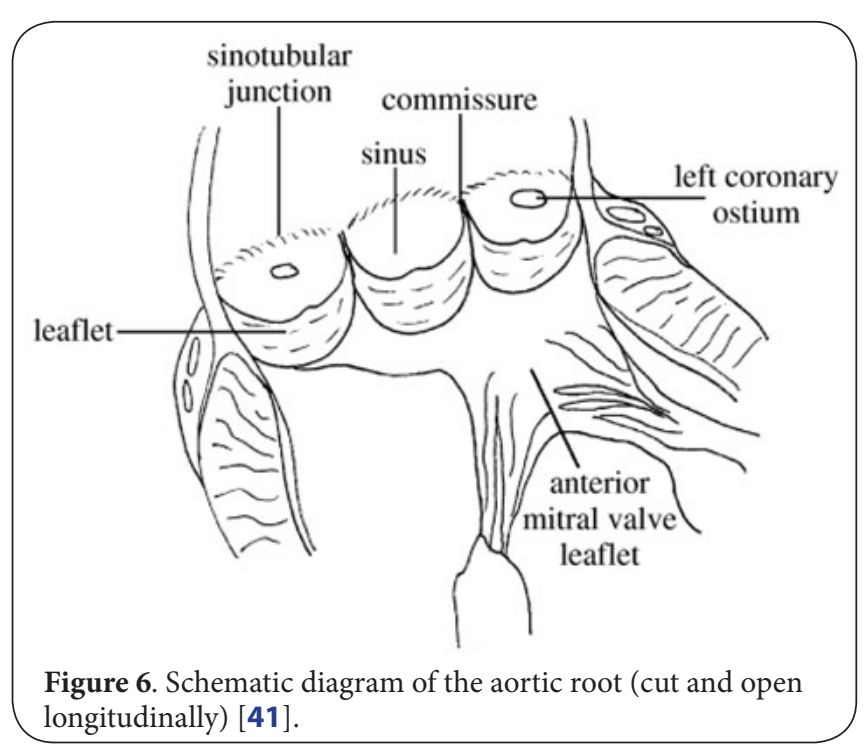


muscular tissue except for its apex, which is a fibrous structure. The interleaflet triangles may contain a variety of contractile and cytoskeletal proteins such as desmin, vimentin, and smooth muscle a-actin, signifying that these structures may play a major role in the regulation of aortic root function [40-44].

\section{Aortic Sinuses}

In the aortic root right after the valve, there are three nearly symmetrical lumpsor bulges, which are also known as aortic sinuses. They are located between the attachments of the valve cusps and the sinotubular junction. At the base of the aortic root, it is partly made up of ventricular musculature but the sinus wall is mainly made up of the aortic wall and is thinner than the healthy aorta. Two of the sinuses make connections to the coronary arteries at very specific spots and have a significant impact on coronary flow. Generally, the sinuses are named according to their connection to the coronary arteries (coronary ostia) resulting in the right, left, and non-coronary sinus. The non-coronary sinus is the largest one in healthy conditions, which has no connection to any arteries. The location of coronary ostia is not the same for all cases, as the left coronary ostium is located inside the sinus in $70 \%$ of cases, slightly above the sinotubular junction in almost $22 \%$ of cases, and at the level of the junction in $9 \%$ of cases. The right coronary ostium is located in $78 \%$ of cases inside the sinus, $13 \%$ slightly above the junction and $10 \%$ at the level of the junction. Also, there is an additional segment to the right coronary ostium in $75 \%$ of cases [42-45].

The attachment of arteries tothe heart is through a fibrous tissue known as arterial fibre-rings. The structure of this tissue is similar to connective tissue (such as tendons), which have nondistinct boundaries in the region of structural and anatomical attachment of the heart and the aorta. The sinuses hold very dissimilar constituents, but the largest portion of them and the three corresponding layers of the aortic wall (known as tunica intima, tunica media and tunica externa (also known as adventitia)) have similar structures. The internal layer of the intima is made up of endothelial cells thatare oriented in the longitudinal direction of the vessel [46]. The subendothelial connective tissue is positioned inthe same direction as the endothelial cells. This layer is separated from the intima by the membrana elastica interna. The media is made up of ring-shape structures such as elastic fibres, smooth muscle cells, collagen fibres (mostly type II and III) and proteoglycans (PGs). The adventitia is the outer layer, which is detached from the intima by the membrana elastica externa. The elements of the externa are similar to theintima, which are oriented longitudinally and are made up of collagen fibres (mostly type I). The wall of the sinuses has the same microstructure whose wall thickness is considerably thinner than that of the ascending aorta [47].

\section{Sinotubular Junctions}

The easily identifiable fold at the top of the sinus is the sino- tubular junction. The transition from the aortic root to the ascending aorta takes place in this region. The sinotubular junction passes through the upper part of each individual commissure and subsequently indicates the upper end of the connection of each valve cusp. It should be noted that dilation of the aortic root at this level canlead to aortic insufficiency [48-50]. The sinotubular junction has similar microstructure to the sinuses and the ascending aorta. The sinus wall is significantly thinner than the wall thatrepresents the fold as the higher portion of the aortic root.

\section{Leaflets}

The native aortic valve has three semi-lunar soft-tissue leaflets or cusps: the left coronary leaflet, the right coronary leaflet and the non-coronary leaflet, following the names of the sinuses they correspond to. The basal attachment region of the leaflets forms the annular ring of the aortic valve, which is located between the left ventricle and the ascending aorta. In the fully closed position, the three leaflets come into contact on their free edge to a nodulus known as the coaptation zone. Each leaflet includes outer endothelial layers and interstitial cells scattered in the matrix, known as the interstitium $[\mathbf{4 1 , 4 9 ]}$. The matrix is located between the endothelial layers. Interstitial cells are spindle shaped and are composed of a variety of fibroblasts, smooth muscle cells and myofibroblasts. Furthermore, endothelial cells have a cobblestone-like structure. The fibrosa, suggested to be the major structural layer, is located on the aortic side and has considerable surface rippling due to the presence of collagen in the form of thick and long bundles and fibers. These collagen bundles and fibers are embedded within an elastin matrix. The orientation of these fibers and bundles are in thecircumferential direction, which results in a soft structure. It is noticeably stiffer and stronger in the circumferential direction when compared to the radial direction. The ventricularis, which is located on the ventricular side, is smooth and mainly made up of elastin and collagen. However, it is moderately flabby and soft due to the absence of structural organization, unlike fibrosa. Spongiosa is the central layer andis mainly made of water similar to hydrogels. This layer also contains glycosaminoglycans and a small amount of elastin and collagen fibres [50-53].

The leaflet layers are highly heterogenous and there is considerable blending of these layers with each other and with the extracellular matrix. The fibrosa covers the whole leaflet and consists of almost $50 \%$ collagen (90\% Type I collagen) by dry weight and $10 \%$ elastin. The ventricularis covers all but the coaptation region where two adjacent leaflets contact and consists of almost $50 \%$ collagen ( $90 \%$ Type I collagen), $20 \%$ elastin. The fibrosa's structure is oriented in the circumferential direction shown in Figure 7 [54].

Available thickness data for aortic valve leaflets shows considerable inconsistency between various studies. The mean thickness has been reported to range from $0.57 \mathrm{~mm}$ at the leaflet edge to $1.20 \mathrm{~mm}$ at the leaflet base in healthy human 
Mohammadi et al. Cardiovascular System 2017,

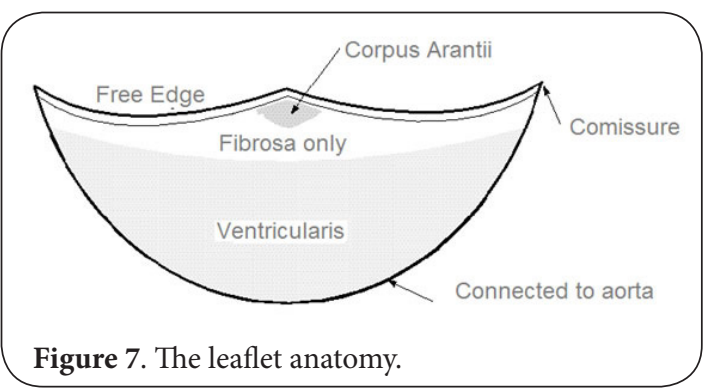

tissues. The thickness was found usingdifferent techniques such as scanning acoustic microscopy, X-ray attenuation technique, etc. When using the $\mathrm{X}$-ray attenuation technique on the porcine valve, mean thickness has been reported to be nearly $0.8 \mathrm{~mm}$ at the base and $0.4 \mathrm{~mm}$ in the rest of the leaflet. Also, there is a correlation between the leaflet thickness and the hydration level of the tissue sothat the mass of the leaflet highly depends on the time during which the tissue is exposed to. An example of this would be dextran solutions with varying concentrations. In this case, immersionof the tissue in high-concentration dextran solutions decreases the mass of the tissue, whereasimmersion of the tissue in low-concentration solutions increases the tissue mass. This indicatesthat the aortic valve leaflet tissue willingly obtains or loses fluid volume by osmosis. The change in fluid volume in fibrosa and ventricularis is not as much as that of in spongiosa. In fact, significant amount of this change in fluid volume occurs in spongiosa. It is suggested that the source of this osmotic pressure gradient is because of the high concentration of glycosaminoglycans, known as GAGs. GAG fibers are hydrophilic polysaccharides placed in the ECM of spongiosa. The GAG content of bioprosthetic aortic valve leaflets, such as porcine valves, is decreased during implant preparation. However, lack of GAG fibers may result in failure of prosthetic valve leaflets. The estimation of glycosaminoglycan content during bioprosthetic valve preparation can be attained by measuring osmotic swelling using a high-frequency ultrasound, which is non-destructive [55-61].

In ultrasound-basedtechniques, the main source of ambiguity in the leaflet tissue thickness evaluation is the unknown speed of sound in the tissue. Using scanning acoustic microscopy, it has been foundthat the speed of sound is nearly 1620 , 1550 and $1590 \mathrm{~ms}^{-1}$ for fibrosa, spongiosa and ventricularis, respectively, in a normal, formalin fixed human aortic valve leaflet tissue. It should be noted that fresh leaflet tissues are better hydrated than fixed tissues, and the speed of sound in $20^{\circ} \mathrm{C}$ water is $1480 \mathrm{~ms}^{-1}$. If the leaflet is considered as a monolayer and homogenous structure, the pulse-echo measurement method can be implemented to assess the average sound speed in the tissue. However, the sound speed can vary in different layers by a factor of 5\% [62].

The aortic valve cusps are covered by a continuous layer of endothelial cells which provide a smooth surface on the ventricular side (i.e., ventricularis) and multiple rims on the arterial side, (i.e., fibrosa). The endothelial cells on the cusps and the entirety of the vascular systems are connected to each other in a similar fashion. The only difference is that the endothelial cells on the leaflets are aligned in the direction of flow. This is unlike the endothelial lining pattern in the other locations of the vascular system wherethe cells are aligned perpendicular to the direction of flow. This particular arrangement of the endothelial cells is due to a biaxial pressure load on the leaflet tissue and wall shear stresses in all blood vessels. Between the ventricularis and fibrosa (i.e., ventricular and aortic surfaces), five layers of connective tissue are identifiable: lamina radialis, lamina ventricularis, lamina fibrosa, lamina spongiosa, and lamina arterialis. The lamina ventricularis is considered as a supplementary layer that is found between the ventricular endothelium and the lamina radialis [63]. Generally, three discrete layers, the lamina radialis, lamina spongiosa and the lamina fibrosa are easily identifiable. The connective tissuesare mechanically attached to each other and forma well-defined sponge-like structure. It has been suggested that this special microstructure is effective inreorganizingcollagen'sintial construction after the external pressure load is removed. The arterial layer holdsgrainy bundles of collagen fibres thatare oriented circumferentially. These construct the macroscopical folds analogous to the free edge of the cusps. This optimal arrangement of fibresis is highlyeffective in transferring the externalload of the cusps to the base and eventually to the wall of the aortic root. The main cells in the leaflet tissue are known as interstitial cells, which are located in the extracellular matrix. These cells are originallyconsidered as smooth muscle cells and exhibitfeatures of both fibroblasts and smooth muscle cells (myofibroblasts). It should be noted that they have similar mechanical properties to fibroblasts or smooth muscle cells. As well, they are significantly effective in the regular function of the aortic valve and undertakedimensionalchanges during the closing and opening phases [64-69].

\section{Dynamics of Cardiac Aortic Valve}

The aortic heart valve is a unidirectional valve thathas two primary functions. The first is that it allows a pressure differential to form between the left ventricle and the aorta when it is closed. When ventricular systole takes place, the pressure in the left ventricle is increased due to contraction of the myocardium in the left ventricle. The increase of the ventricular pressure continuesto the point whereit exceeds the pressure in the aorta. In this stage, the high ventricular pressure causes the aortic valve to open, which normally takes between 20 to $30 \mathrm{~ms}$. The second is that in the opening phase, the valve controls the direction of blood flow to be in only one direction. It also controls the passive transport due to the pressure differential, which allows the oxygenated blood to enter the aorta and the systemic circulation of the body. The closing phase starts at the beginning of diastole when 
the left ventricle dilates and fills from the left atrium. These opening and closing phases of the native aortic valve are vital for theproper dynamic transport of oxygenated blood [70].

Due to the pulsatile nature of the blood flowing through the valve, the blood reaches its maximum velocity after the leaflets have fully opened in the first half of the systolic phase. During the second half, the flow rate decreases quickly. The small pressure gradient that is developed affects the low momentum fluid near the wall of the aortic root more than that at the centerline. This causes a reverse flow in the sinus region, which has an irregular concaved-like morphology. This reverse flow increases during the closing phase and impacts the valve at the start of diastole, as shown in Figure 8 [71].

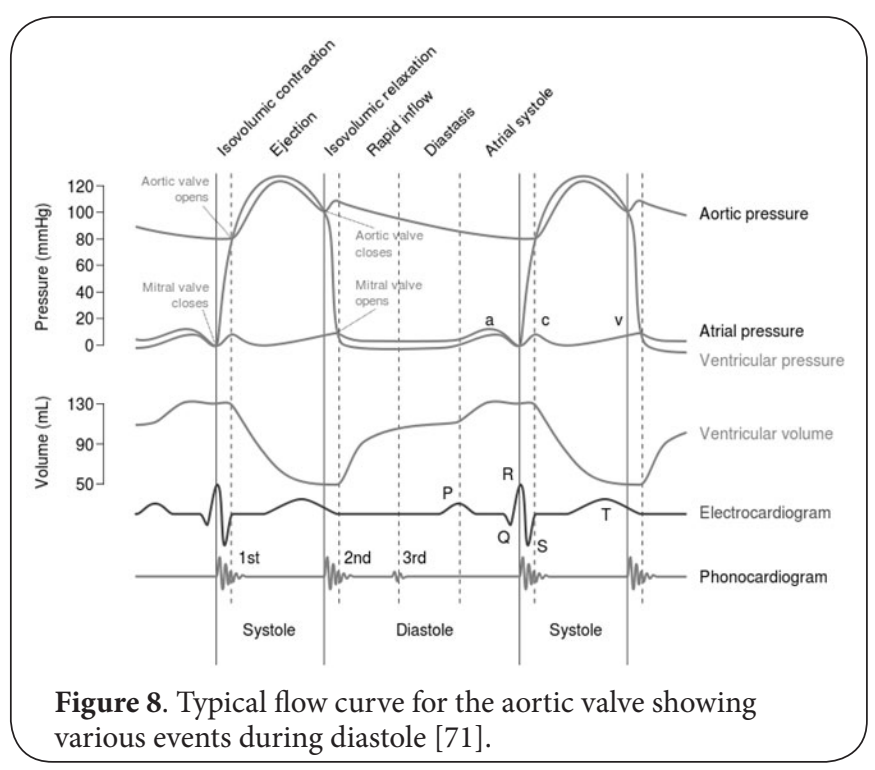

During systole, vortices and secondary circulation zones develop in all three sinuses right behind the leaflets of the aortic valve, which significantly assists in a quick and efficient valve closure. The backflow volume (or the regurgitation flow during closure) has been shown to be less than $5 \%$ of the forward flow in native valves, more for prosthetic valves. This period of reverse flow can be measured using experimental means, such as Doppler ultrasound techniques or computational methods [72].

In each cycle atthe end of the closing phase, there is a massive impact, known as hammer pressure, which is applied on the aortic side of the valve, i.e., fibrosa. This pressure is a typical force experienced by a valve in the aortic position and is similar to the water hammer effect. This load is a pressure induced force caused by the kinetic energy of moving blood when it is forcedto stop or change direction rapidly. For native aortic cardiac valves, this closing phase takes about $35 \mathrm{~ms}$ and the impact lasts foralmost $5.8 \mathrm{~ms}$.

\section{Heart Valve Tissue Oxygenation}

The partial pressure of oxygen has a controlling effect on the valve leaflet tissue repair and therefore helps determine the structural integrity and/or durability of the aortic heart valve leaflet tissue. It has been suggested that heart valve interstitial cells preserve valve tissue homeostasis through a controlled extracellular matrix, mostly by collagen biosynthesis. It is importantto understandthe relation between the oxygen tension in the valve tissue and the leaflet cells biosynthetic activity. The existence of a blood supply and capillary network within aortic valve leaflet tissue suggests that oxygen delivered to the tissue by diffusion is not enough. More oxygen is delivered to the cusps by microcirculation [70-73].

It is known that aortic valves possess significant mechanical properties in order to function.A large cellular population, including mostlyfibroblasts and myofibroblasts, are present in the leaflet tissue. This implies that oxygen factors, such as consumption $\left(\mathrm{VO}_{2}\right)$ or diffusion $\left(\mathrm{DO}_{2}\right)$, of the valve leaflet tissue need to be taken into consideration. Unfortunately, for different vascular structures, these values are not available as they have not been measured. For example these values for the dog femoral artery at body temperature $\left(37^{\circ} \mathrm{C}\right)$ is $\mathrm{VO}_{2}=1.8 \times 10^{-4} \mathrm{~mL} \mathrm{O}_{2} \times \mathrm{mL} \mathrm{O}_{2} \cdot \mathrm{mL}$ tissue ${ }^{-1} \cdot \mathrm{s}^{-1}$ and the for dog aorta adventitia $\mathrm{DO}_{2}=11.4 \times 10^{-6} \mathrm{~cm}^{2} \cdot \mathrm{s}^{-1}$. Also, as an important oxygen parameter in the leaflet tissue, the solubility of oxygen within the tissue needs to be taken into account.The solubility of blood in plasma at body temperature $\left(37^{\circ} \mathrm{C}\right)$ is $2.82 \times 10^{-5} \mathrm{~mL} \mathrm{O}_{2} \cdot \mathrm{mL}_{\text {tissue }}{ }^{-1} \cdot \mathrm{mm} \mathrm{Hg}^{-1}$. In addition, water content of the valve leaflet tissue is $90 \%$, sosolubility of oxygen in the valve leaflet is then calculated to be $90 \%$ of that for plasma, $\mathrm{k}=2.54 \times 10^{-5} \mathrm{~mL} \mathrm{O}_{2} \cdot \mathrm{mL}$ tissue $\mathrm{e}^{-1} \cdot \mathrm{mm} \mathrm{Hg}^{-1}$. On the basis of these oxygen transport factors and assuming that $\mathrm{PaO}_{2}$ is $100 \mathrm{~mm} \mathrm{Hg}$, the assessed maximum distance that oxygen can be supplied from the leaflet surface into the tissue is nearly $0.2 \mathrm{~mm}$. The significant amount of oxygen delivered through the vascular supply of the aortic valve is locatedmainly at the valve base. This is because tissue thickness is high,ranging from 0.692 to $0.860 \mathrm{~mm}$. It is assumedthat the oxygen transport properties,such as diffusivity and solubility of oxygen within the tissue, and the metabolic requirements of the valve are closeto those of other vascular structures. By assuming this,is clear that an oxygen supply route, such as microcirculation, in addition to that of diffusion from the leaflet surfaces is required for places where the leaflet tissue thickness is higher than a certain value [73].

Given that the thickness of the leaflet tissue is highly variable, the largest part of the leaflet receives the necessary oxygen by diffusion from the blood stream surrounding the valves. However, if the thickness is higher than a given value, the leaflet tissue may need an additional oxygen supply route. This route would be through the microcirculation and micro arteries in the tissue. This is due to the collagen content in the leaflet, which changes the thickness of the leaflet locally. The area of the leaflet is comprised of large amount of collagen fibers in the form of bundles that reach an average thickness of $0.2 \mathrm{~mm}$. The corrugated surface of the leaflets due thepres- 
Mohammadi et al. Cardiovascular System 2017,

http://www.hoajonline.com/journals/pdf/2052-4358-5-2.pdf

doi: $10.7243 / 2052-4358-5-2$

ence of collagen bundles also provides a larger surface, which can increase the available surface for oxygen to be delivered to the tissue via diffusion. Also, when a leaflet is loaded or unloaded due to systolic and diastolic pressures, it will affect the tissue thickness. The change in thickness is not prevalent in the base regions, but can be up to $40 \%$ in the other regions of the leaflet tissue. This relatively high thickness change in the areas far from the base region explains why oxygen is supplied only by diffusion there and that microcirculationand presence of micro arteries is not required. Another point to take into consideration is when two adjacent leaflets come to contact at the end of systole, one side of the leaflets becomes passive and would no longer be able to receive oxygen from both sides of the tissue via diffusion [74].

The microcirculation components and micro arteries thatare present close to the base are mostly capillaries and areknown as the capillary bed.However, the presence of arterioles and venules has been also reported. This bed is located mostly in the spongiosa layer, which is almost in the middle of the leaflet. The presence of the microcirculation at any location in the leaflet indicates that the partial pressure of oxygen due to diffusion is considerably low. As such, micro arteries are required to supply additional oxygen to the tissue. In addition, the density of the micro arteries may vary from location to location in the leaflet tissue,enough that almost $30 \%$ of the base region and nearly $3 \%$ of other leaflet areas are vascularized. It has been shown that the density of the micro vessels in the base of the left coronary leaflet is 4.9 vessels $/ \mathrm{mm}^{3}$, whereas in the other layers, such as the noncoronary and right coronary leaflets, it is almost the same at 5.1 vessels $/ \mathrm{mm}^{3} . \mathrm{In}$ the regions relatively far from the base, the density of micro vessels decreases to approximately 0.66 vessels $/ \mathrm{mm}^{3}$ [70-75]

Given that the major factor in oxygen supply and demand is the thickness of the leaflet tissue, it should be noted that the metabolic rate within the tissue is just as important. The metabolic rate of the tissue depends on the state of the tissue,as damage and repair may significantly affect the metabolic rate. Therefore, metabolic rate plays a major role in the oxygen supply to the tissue and the tissue composition, including the formation of microcirculation and micro vessels [76].

These factors are extremely important in tissue engineering of heart valve leaflet tissue. Given the porous structure of a scaffold and cells sitting sporadically within the scaffold, a full understanding of leaflet function, anatomy, state, and oxygen demand and supply for cells is necessary. In general conditions with a normal metabolic rate, an overall thickness of nearly $0.4 \mathrm{~mm}$ is enough for a leaflet to obtain its essential oxygen via diffusion. A good example is the comparison between the aortic valve and the pulmonary valve in the Ross Procedure. The Ross Procedure is a particular aortic valve surgery in which the patient's diseased aortic valve is replaced with his or her own pulmonary valve. The pulmonary valve is then replaced with a xenograft valve or a cryopreserved cadaveric pulmonary valve. Since the pulmonary valve leaflets are thinner, that they can function well within the high-pressure and oxygen-rich environment of the left ventricle and the aortic root, in spite of the loss of blood supply. This is because of the pulmonary valve's capability to receive enough oxygen through diffusion only from its surfaces in the new position. Also, the new environment has a higher partial pressure of oxygen compared to the previous i.e., native $\mathrm{PO}_{2}$ environment in the pulmonary circulation is $40 \mathrm{~mm} \mathrm{Hg}$ whereas the pressure in the aortic root is $100 \mathrm{~mm} \mathrm{Hg}$. Valve leaflets are complicated structures with a precise balance of components, soa slight change in geometry and composition can lead to significant functional effects. Due to this,tissue characteristics, cellular density,oxygen consumption and diffusion properties must be well understood. This is essential for the application of tissue engineering of the heart valve leaflet tissue [77].

\section{Mechanical Characterization of Aortic Valves}

The aortic valve is a unidirectional and almost passive checkvalve that controls the direction of blood flow from the left ventricle to the rest of the body through the systemic circulation. Mechanical stresses such as tensile, shear and bending stresses are high and time-dependent as they change very quickly during the opening and closing phases. Each heart beat, known as a cardiac cycle, causes one time opening and one time closing on the aortic valve. This takes almost 0.83 seconds. This cycle repeats approximately 100,000 times a day and almost 3.72 billion times in an average lifetime. A cascade of biochemical and biomechanical events at the molecular and cellular leveloccurin order for the aortic valve to maintain its function. In fact, any types of valve abnormality (which could be congenital or due to disease or trauma) affect its function in a substantial way.The extracellular matrix (ECM), the main portion of the leaflet tissue, is the extracellular part of multicellular structure that provides structural, biochemical and biomechanical support to the tissue cells. Asmulticellularity evolved independently in different multicellular roots, the composition of the ECM differs between multicellular structures; however, cell-to-cell communication, cell adhesion and differentiation are common functions of the ECM. The ECM within the heart valve leaflet tissue mainly consists of collagen, elastin, proteoglycans (PGs), and glycosaminoglycans (GAGs). The ECM plays a major role in the unique mechanical properties of the valve tissue and the overall valve function. Within the ECM, there is another protein known as pericellular metrics (PCM). PCM bonds with and immediately surrounds the cells. The role of PCM is to serve as a source of ligands for cells receptors. When the leaflet tissue is under external loads, PCM transfers these mechanical forces to the cells and develops intracellular signaling pathways. There are multiple types of ECM with different distinctive mechanical properties so that a variety of micromechanical environments are available for the tissue cells. This is significant because there is strong hypothesis that the tissue cells react to mechanical 
Mohammadi et al. Cardiovascular System 2017,

signals and consequently adapt gene expression and protein production. Also, ECM can easily link with soluble molecules in the ECM, e.g., growth factors, so it can host variety of bioactive factors which are influential on cell behavior. Any changes in the composition of the ECM are significant because it may lead to heart valve disease and/or majorly affect the valve functions [78].

The valve leaflet is soft and flexible andhas a layered, complex and heterogeneous architecture. Three distinct layers are identifiable, two of which are known as structural layers: fibrosa and ventricularis. The third layer is a non-structural layer which is located in between fibrosa and ventricularis, known as spongiosa. Like other tissues, the leaflet tissue has an extremely specialized, functionally adapted extracellular matrix. The mechanical properties of the valve tissue have direct impact with the composition of the matrix, including collagen, elastin and PGs. It is important for the heart valve leaflet tissue to be soft and flexible when unloaded, but nearly inextensible, strong and stiff when fully loaded. The design features of the leaflet tissue include a rippling surface, which is like an array of collagen fibers and bundles in fibrosa elongated from one commissure to the other commissure. Elastin and collagen are the main proteins that provide mechanical characteristics of aortic heart valves. Elastin is a protein which is structurally available in sheets, tubes or fibers. It is highly extensible and elastic, having a stiffness of almost 2100 times less than collagen fibers. Given that elastin has a relatively low mechanical stiffness, its energy loss in cyclic loading conditions is extremely low. It is so low that that it is considered to be the purest natural elastic material. The maximum load and force on the leaflets is when the valve is fully closed, which happens in the diastolic phase. In the very early stages where load is small, the tissue offers a very small resistance to elongation. In this stage, only elastin fibers provide mechanical strength and force transmission. In this stage, elongation of the tissue is relatively high and collagen fibers are coil-like structures. Upon load increase, the collagen fibers start to uncoil and gradually stretch. As the strength and stiffness of the tissue increases, the amount of force on the tissue also increases, and accordingly more collagen fibersuncoil. In this stage, elastin fibers do not contribute to the mechanical characteristics of the tissue.In addition, elongation of the tissue is consistently low and the main elements providing mechanical strength are collagen fibers. In excessive loading conditions, when the force would further increase,the tissue cannot tolerate it and eventually ruptures. When the tissue tears apart, the corrugations completely flatten and the crimps of the collagen fibers become oriented in the radial direction. In a complete cardiac cycle, the leaflet dimensions changes between the systolic anddiastolic phases, but there is no change in dimensions during systole or diastole (Figure 9) [70-80].

The attachments of the three layers are made ofelastin fibers that are distributed in the entire leaflet tissue. Elastin also provides intrafibrillar binds between collagen fibers and

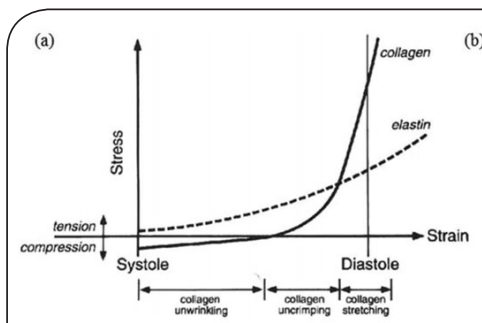

(b)

Figure 9. (a) Mechanical behavior of collagen and elastin fibers during the cardiac cycle and (b) the morphology of the aortic leaflet during the opening and closing phases, i.e., systole and diastole [81].

bundles in the fibrosa layer, and in addition forms a threedimensional interconnected network in the spongiosa layer. When the tissue is unloaded, these networks cause the collagen fibers to return to their wavy and crimped shape in the three layers of the valve tissue. The particular roll of each layer is varying. Fibrosa is thought to be load bearing due to the presence of collagen fibers. The role of spongiosa is conferring flexibility, dampening vibrations from closing, and resisting delamination due to the presence of glycosaminoglycans and proteoglycans. The role of ventricularis is restoration of the wavy and crimped state of collagen fibers in ventricularis due to its high amount of elastin [82].

Aortic heart valve leaflet tissues are highly nonlinear, anisotropic and heterogeneous. These properties have been developed according to the physiological conditions of the valve and are consistent with the mechanical environment in which the valve functions. The two main directions in which the mechanical properties of the valve leaflet tissue are focusedare the commissure-to-commissure direction (known as the circumferential direction) and the radial direction (perpendicular to circumferential). During diastole, when the load applied on the tissue is maximum, collagen fibers and bundles in the fibrosa layer are the layer responsible fortolerating nearly $80 \mathrm{mmHg}$ pressure. In order for the leaflet tissue to withstand such a high tensile load, collagen fibers bond together. They formparallel collagen bundles that are aligned in the circumferential direction. Although the collagen fibers have nearly $1-2 \%$ yield strain, the crimping and waviness of the fibers allows the fibrosa to tolerate approximately $40 \%$ strain in when fully loaded. Flattening of wavy fibers provides nearly $17 \%$ strain capacity, whereas the waviness allows additional nearly $23 \%$ strain capacity. During the opening phase, leaflets are relaxed and elastin maintains the mechanical strength of the leaflet tissue. In this phase, collagen fibers return back to their original wavy and crimped shape and the surface area of the tissue isdecreased. Spongiosa, which mainly consists of GAG fibers, enables the rearrangement of the collagen and elastic fibers, diminishes vibration, dissipates energy from closing, provides a smooth contact between the leaflets, and prevents delamination between layers [80].

In case of diseased aortic valves, for example; the calcific 
Mohammadi et al. Cardiovascular System 2017,

http://www.hoajonline.com/journals/pdf/2052-4358-5-2.pdf

doi: $10.7243 / 2052-4358-5-2$

aortic valve, collagen fibers and bundles as well aselastin fibers in the fibrosa layer are disrupted and disordered. Due to this proteoglycan deposition is increased. ECM remodeling occurs because of matrix metalloproteinases and the potent elastase cathepsin S, which are composed ofmacrophages. Also, in calcific fibrosa, osteocalcin and osteonectin, which are bone proteins, are found in the tissue. These proteins accelerate mineralization and cause the osteoblastic differentiation of valvular interstitial cells [81].

\section{Calcification of the Heart Valve Tissue}

Aortic valve calcification is a condition where calcium deposits accumulateon the aortic valve. These deposits can cause (1) weakening of the structure of the leaflet tissue, and (2) narrowing at the opening of the aortic valve. This narrowing can become significant enough that it may reduce blood flow through the aortic valve, a condition called aortic valve stenosis.Aortic valve calcification may be an early sign for a heart disease, even if the patient does not have any other heart disease symptoms. Generally, calcification and stenosis affect patients who are 65+ in age. However, when it occurs in younger patients, the reason might be acongenital heart diseaseor kidney failure. Calcification is one of the significant issues leading to the mechanical failure of tissue heart valve replacements. After treating tissue valves with glutaraldehyde, calcification originates primarily within remainingcells that have been devitalized. In this process, the tissue is covered with calcium phosphate mineraldeposits through a reaction of calcium-rich extracellular fluid with phosphorusin the tissue. Calcification of the heart valve leaflet tissue and mineralization of bone are precisely the same concept. There have been many studies as to how to prevent calcification in the heart valve leaflet tissue, which are summarized into 4 categories: (1) Making a stable link between calcificationinhibitors and glutaraldehyde fixed tissue, (2) Removing ormodifying calcifiable agents, (3) Modifying glutaraldehyde fixation, and (4) Usinganother tissue cross-linker other than glutaraldehyde [80-82].

Calcification ofthe aortic valve is a slow process. Itwas initially thought to be a deteriorating mechanism because of the vigorous wearandtear of the leaflet structures. In this mechanism, calcium is passively deposited on the leaflets. Based oncomprehensive histopathological and clinical data,it is known that calcification process in aortic valves is an active disease similar to atherosclerosis with chronic inflammation, lipoprotein deposition, and active leaflet calcification. In the early stages, variation of mechanical forces, such as shear stress, may form a notch on the aortic valve leaflets as a result of endothelial disruption. The state of normal and shear stresses is influential on the calcification initiation and progression on the tissue. Normal stresses are highest on fibrosa near the attachment of the leaflets and the root at the beginning of the systolic phase, simply because the leaflets act like a cantilever beam. Among the three sinuses, shear stress is low- est on the endothelium layer in the noncoronary sinus of the root. This is due to drag force being less due to hemodynamic conditions around the coronary outlets, which justifies why the noncoronary leaflet is affected more intensely than the other two leaflets. Also, if two of the leaflets fuse together, the calcification process is accordingly affected. Patients with bicuspid valves are subjected to higher shear and normal stresses, which lowers the calcification process considerably. However, almost all patients with bicuspid valves develop significant hemodynamic complications over time leading to aortic stenosis, which is not the case for patientswith a trileaflet valve (Figure 10) [80-82].

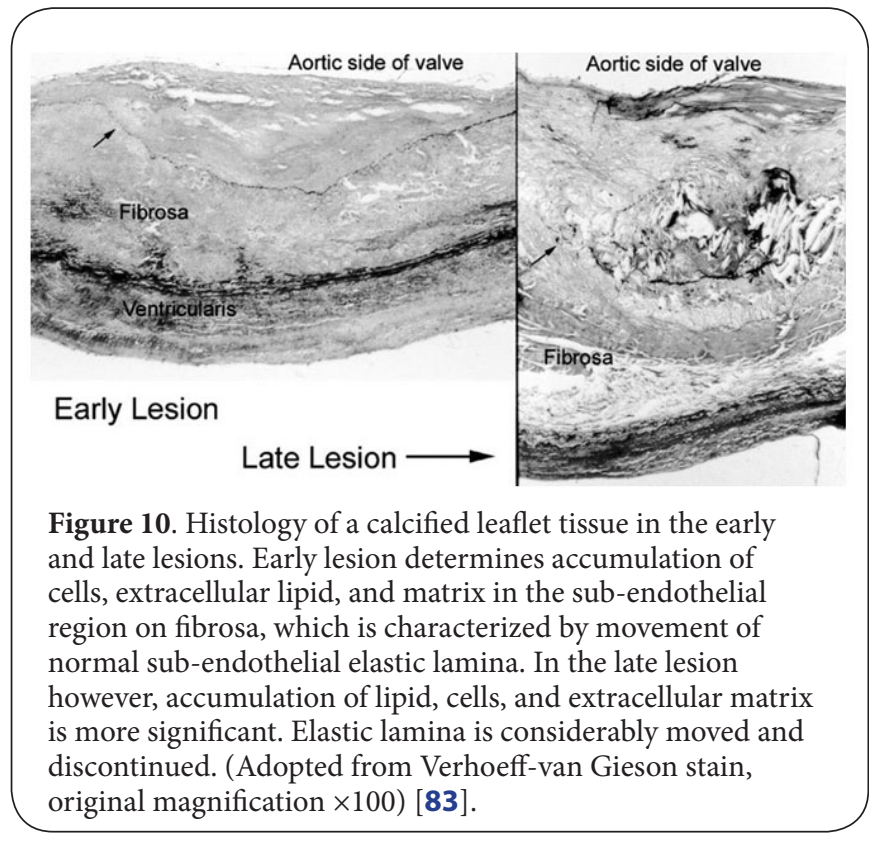

In the early stages, extracellular lipid accumulation is observed in several minor regionsunder the endothelial layer, also known as sub-endothelial level. In this stage, the elastic lamina is displaced and extended into the nearby layer, i.e., fibrosa. There is histological evidence indicating that plasma lipoproteins are the source of these lipids. The formation of foam cells takes place whenadapted low density lipoprotein (LDLs), which are related to proinflammatory and growthstimulatory properties, are taken up by macrophages.

In the early stages, inflammatory cells includingT lymphocytes and macrophagesplay a major role in the calcification process. Macrophages are differentiated from monocytes, which have been penetrated to the endothelial layer by adhesion molecules. T lymphocytes are activated within the subendothelium and fibrosa and then release cytokines. Cytokines include transforming growth factor- $\beta 1$ and interleukin- $1 \beta$, which is a proinflammatory cytokine related to matrix metalloproteins. All of these proteins contribute to the formation of extracellular matrix, remodeling, and focal calcification [72]. 
Angiotensin-converting enzyme (ACE)is also identifiable in the calcification process. It can be formed locally or extracellularly and colocalized with apolipoprotein B. The colocalized ACE with apolipoprotein $B$ is a module of taken LDL particles, which implies that the ACE could be carried into the lesion via LDL cholesterol particles. Moreover, angiotensin II, which is the promoted version of monocyte infiltration and the uptake of modified LDL within atherosclerotic lesions, is observed in the early stages of the calcification process. This suggests that ACE is active enzymatically. Also, a fraction of fibroblasts within the fibrosa is transformed into myofibroblasts, which are similar to smooth muscle cells with expression of a-actin, desmin, and vimentin. In advanced stages, angiotensin type-1 receptors form on a fraction of the myofibroblasts that express $\alpha$-actin, further reinforcing that ACE detected is active enzymatically [72-75].

In the early stages of the calcification progression, the process is active and quick, which essentially leads to the leaflet hardening and severe stenosis. In areas where lipoprotein is built-up and inflammatory cells are infiltrated, microscopic regions of calcification are observed. Matrix vesicles (the location of calcification) are released when valvular fibroblasts are stimulated by oxidized LDL. A protein which participates in bone formation, osteopontin, is expressed by macrophagesin which the level of mRAN expression is proportional to the level and location of calcification. A portion of myofibroblasts consists of osteoblast phenotypes, which participate inthe development of calcific nodules. The formation of these nodules is increased once the myofibroblasts are exposed to oxidized $L D L$ and transforming growth factor- $\beta 1$.During the calcification progression, deposition of calcium on the leaflet continues in a rapid way, which is the same as bone formation. For significant number of patients $(\sim 85 \%)$, the type of calcification is dystrophic.For the remaining $15 \%$ of patients, it is lamellar or endochondral bone tissue where hematopoietic marrow and remodeling are evidenced. Bone tissues on the leaflets lead to expression of factors promoting osteogenesis. In patients with increased bone demineralization or osteoporosis, the occurrence of calcification is higher. This is thought to be related to ectopic calcification or an increased body mineral turnover. The calcification progression may be controlled by factors such asconnective tissue growth factor, polymorphisms of interleukin-10, and chemokine receptor-5 [76].

Calcification is also an issue with bioprosthetic valves. However, the occurrence of calcification innative valve failure appears to increase with age, which is in contrast to tissue native valves. This inconsistencyproposes that the calcification process of bioprosthetic valves is unlike the process perceived in native valves [77].

\section{Aortic Valve Disease}

Valvular heart disease is any disease involving one or more heart valves (the aortic and mitral valves on the left and the pulmonary and tricuspid valves on the right). Valve problems may be congenital or due to other causes later in life.

\section{Congenital Valve Disease}

This type of valve disease most often affects the aortic or pulmonary valve due to geometrical issues. These include an abnormal size of the valve, the issues with the leaflet geometry or the way they are attached [75-77].

In the aortic valve, two of the leaflets may fuse together and play the role of one, which is known as bicuspid aortic valve disease. In this case, instead of the normal three leaflets or cusps, the aortic valve has only two leaflets. This can reduce the compliance of the valve and leaflets, which in turn negatively affects the dynamics of the valve in the closing and opening phases. One of the issues of bicuspid aortic valve diseases is the leakage due to the non-parallel contact between the two leaflets [75-77].

\section{Acquired Valve Disease}

A range of diseases and infections, such as endocarditis or rheumatic fever, may affect the structure and composition of normal valves which is also known as acquired valve disease (Figure 11).

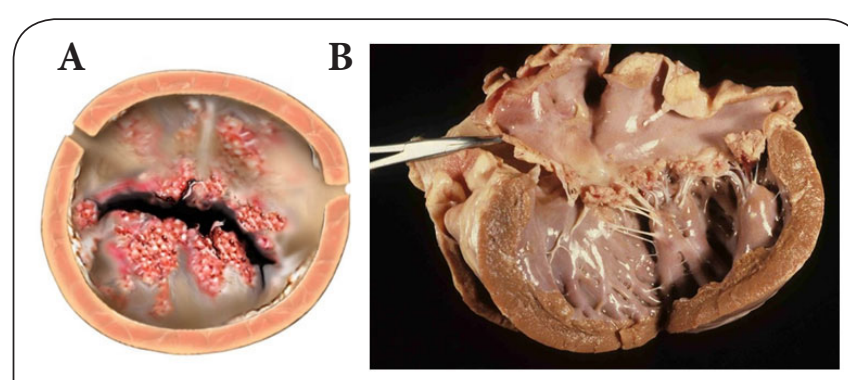

Figure 11. Diseased aortic valve: (A) Rheumatic Fever, and (B) Endocarditis [84].

An untreated bacterial infection, which is usually strep throat, might be the reason for rheumatic fever. The initial infection typically happens in children and is the origin of inflammation of the heart valves. However, symptoms associated with the inflammation may become apparent $20-40$ years later. Also, the presence of bacteria in the bloodstream for whatever reason may cause endocarditis. This may cause growths and holes in the valves and scarring, which in turn causes leakage in the closing phase [78].

Some of the geometrical or structural issues associated with the diseased valves are: (1) the chordae tendinae or papillary muscles may stretch or tear, (2) the annulus of the valve can dilate and become wide due to structural deficiencies, and (3) the valve leaflets can become stiff, fibrotic and calcific [85].

Mitral valve prolapse (MVP) is a geometrical and constructional deficiency of the mitral valve which affects $1 \%$ to $2 \%$ of the population. While the mitral valve cannot hold its structural integrity, the leaflets flop back into the left atrium during diastole (the heart's contraction).In turn, the 
back flow rate and static leakage significantly increases. MVP also causes the tissues of the valve to become abnormal and stretchy, which specifically occurs in the anterior-posterior direction, perpendicular to the transverse direction of the valve (Figure 12).

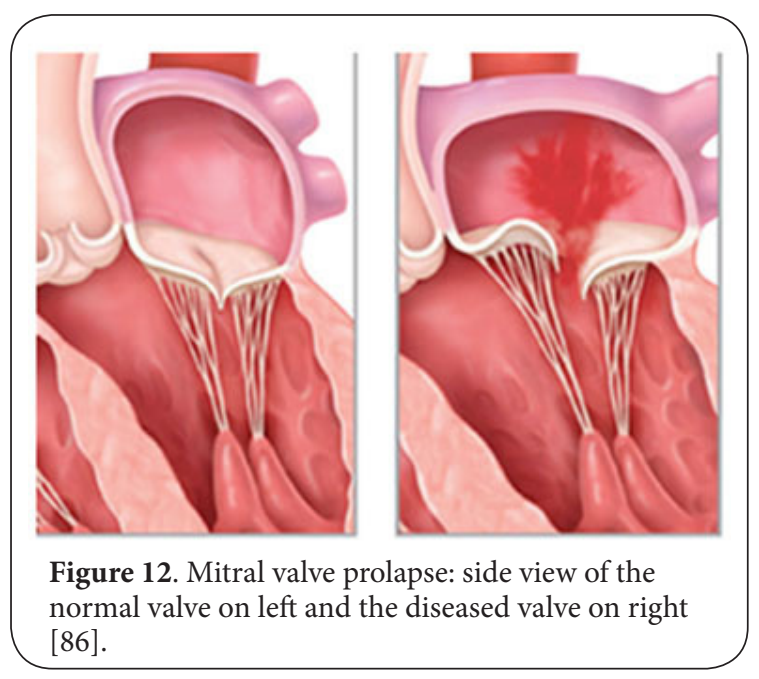

Treatment may be with medication but often (depending on the severity) involves valve repair or replacement. The aortic valve is the heart valve that is the most susceptible to diseases as it sustains the largest pressure difference between the left ventricle and the main aorta. This is neccessary to ensure the oxygenated blood is distributed effectively throughout the arterial system [71].

There are two major diseases that can affect the aortic valve: (1) aortic stenosis, in which the valve fails to open fully, thereby obstructing blood flow out from the heart, and (2) aortic insufficiency (also known as aortic regurgitation) in which the aortic valve is incompetent and blood flows passively back to the heart in the wrong direction. These two conditions frequently co-exist. Whatever the cause of valvular disease, it burdens the heart with an increased work rate to maintain stroke volume. This could lead to: (1) heart muscle dysfunction (including left ventricular hypertrophy), and (2) potential congestive heart failure [72].

\section{Aortic Stenosis}

Aortic stenosis is mainly due to obstruction of blood flow at the aortic valve and does not includethe subvalvular and supravalvular types of this disease. Aortic valve stenosis is typically characterized by restricted systolic opening of the valve leaflets, in which the mean transvalvular pressure gradient is at least $10 \mathrm{~mm} \mathrm{Hg}$. The reason of the stenosis can be also characterized by the anatomy and disease process affecting the valve tissue [72-75].

Two of the major aortic stenosis cases are calcific aortic and congenital bicuspid aortic stenoses. Minor cases include rheumatic aortic and congenital aortic stenoses. Minor thickening and/or calcification of the aortic valve without limited leaflet motion affects around $25 \%$ of the population above the age of 65 . Calcific aortic stenosis, however, affects roughly $2 \%$ to $3 \%$ of the population above the age of 75 . Congenital bicuspid aortic valve stenosis is known to be the main source of aortic stenosis; the estimated overall occurrence of an anatomic bicuspid aortic valve is around $1 \%$ to $2 \%$ of the population. Of these, about $50 \%$ are prone to develop aortic stenosis and up to $30 \%$ will develop aortic regurgitation. Aortic stenosis due to a congenital bicuspid aortic valve is more frequent in men compared to women, but later life calcific disease of the aortic valve affects both genders similarly. Congenital aortic stenosis is typically caused by failure of the valve commissures that causes aortic stenosis, mostly in young adults or children [72-76].

Aortic valve disease such as calcific disease, calcification of the congenital bicuspid valve, and congenital aortic stenosis can be mostly diagnosed clinically by the evaluation of echocardiography data. Calcific aortic stenosis, which is known as degenerative or senile form, involves patients with other risk factors for atherosclerotic disease. The progression of aortic valve disease is a dynamic process, with inflammation, lipid deposition, and calcification. This type of aortic stenosis progresses gradually for the patients between the ages of 70 and 90. Echocardiography is usually effective in finding varying degrees of nodular thickening and calcification of the leaflets with limited systolic motion. Adult patients with congenital bicuspid valves (also known as heart murmur) are mainly men and and is most commonly found in patients between the ages of 40 and 60 . In bicuspid valves, two of the leaflets are typically merged together. This can be diagnosed using electrocardiography by the presence of a raphe, eccentric closure, leaflet doming, and fish mouth orifice during systole. Congenital aortic stenosis in which the valve is either unicuspid or bicuspid typically occurs in children and infants and can be diagnosed using echocardiography data. Minor causes of aortic stenosis includerheumatic disease, radiation heart disease, and homozygous hypercholesterolemia [76] .

Aortic stenosis may cause chronic left ventricular hyper pressure. In all ages, the natural history of aortic stenosis and the functional integrity of the mitral valve are related to one another. As long as sufficient mitral valve function is preserved, the pulmonary bed will not be affected by the systolic hyper pressure caused by aortic stenosis. Contrary to mitral valve disease, in which the pulmonary circulation is directly influenced, compensatory concentric left ventricular hypertrophy permits the hyper-pressurized ventricle to sustain stroke volume with slight growths in diastolic pressure. In some cases, patients may stay asymptomatic for several years [76].

Ultimately, however, left ventricular hypertrophy leads to either diastolic dysfunction with the initiation of congestive symptoms or myocardial oxygen requirements exceeding supply, causing the initiation of angina. In some patients, exertional syncope can occur, possibly reflecting the incapability to increase cardiac output and sustain blood pressure 
Mohammadi et al. Cardiovascular System 2017,

as a reaction to vasodilation [76].

\section{Aortic Regurgitation or Aortic Insufficiency}

Aortic regurgitation is characterized by the ineffectiveness of the aortic valve, causing a portion of the left ventricular forward stroke volume to returnto the left ventricle during diastole. The reason of the regurgitation, as for aortic stenosis, can be further characterized due to the anatomy of the valve, aortic root, and the disease process influencing the valve [77].

Aortic regurgitation is mainly a product of leaflet pathology or aortic root disease, but alsocould also be caused by a congenital unicuspid or bicuspid aortic valve often due to leaflet prolapse. Infective endocarditis affecting the aortic valve may lead to aortic regurgitation because of lack of coaptation, perforation, or leaflet retraction. In fact, aortic root dilation and loss of leaflet coaptation due to any pathological process can lead to aortic regurgitation. As to the related diseases of the aortic root leading to aortic regurgitation, the following diseases can be outlined: annuloaortic ectasia, familial aortic aneurysmal disease, long standing hypertension, hereditable diseases of connective tissue (e.g., Marfan syndrome), and ventricular septal defects as observed in tetralogy of Fallot. Minor conditions includeEhlers-Danlos syndrome, radiation heart disease, inflammatory aortitis, aortic valvulitis developed by giant cell aortitis, syphilitic aortitis, ankylosing spondylitis, reactive arthritis, and rheumatoid arthritis. Chronic aortic regurgitation leads to volume overloading of the left ventricle and, unlike mitral regurgitation, also leads to an increase of pressure in the left ventricle. The volume overload could be insignificantand thereforecause no important symptoms for possibly decades [77]. The consequence of aortic regurgitation is an intense diastolic leak, left ventricular dilation and hypertrophy, where the left ventricle becomes a more spherical shape. The ejection fraction generally is conserved untilthe final stages of the disease. Since patients may resist against severe aortic regurgitation with minimal symptoms, constant careful monitoring of left ventricular dimensions and systolic function should occur. This is because the aortic root and proximal ascending aortic dilation can happen together.

Aortic valve replacement is in order if a patient is symptomatic from either aortic insufficiency or aortic regurgitation, or if the heart begins to expand as tested by echocardiogram.

Other types of valve disease consist of: (1) coronary artery disease, (2) myocardial infarction, (3) cardiomyopathy (heart muscle disease), (4) syphilis, (5) hypertension, (6) aortic aneurysms, and (7) connective tissue diseases. Rare cases include tumors, some types of drugs, and radiation. There are two main options available to remedy the diseased valve: (1) heart valve repair, which leads to tissue engineering and regenerative medicine, and (2) heart valve replacement, which leads to medical devices (Figure 13).

\section{Prosthetic Heart Valves}

There are nearly 350,000 valve replacement procedures annu-

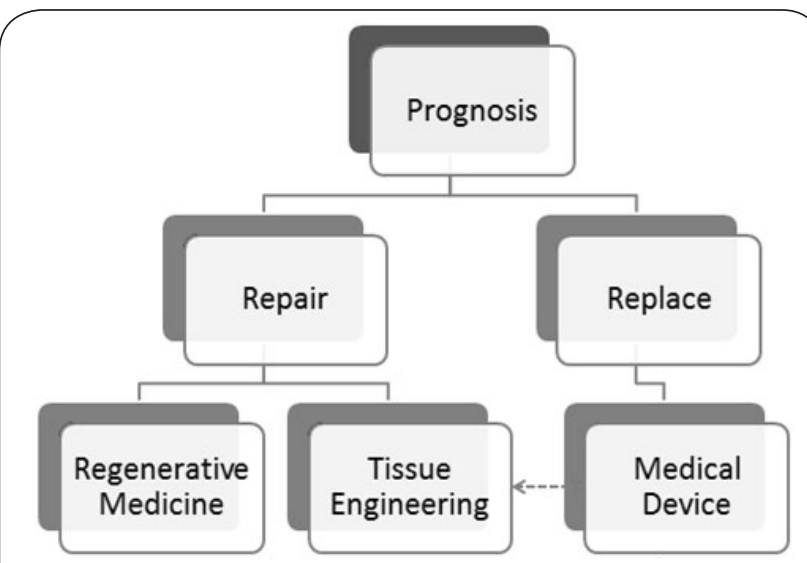

Figure 13. Heart valve disease and available options.

ally worldwide. The age range of the majority of patients with aortic valve pathology in need of replacement is between 60 and 80 . Among the two main aortic valve diseases, replacement for aortic insufficiency, aortic stenosis of $~ 15 \%$ is performed much less frequently than for aortic stenosis of $85 \%$ [1]. As of the related diseases to aortic stenosis, there are several of note, including congestive heart failure, syncope,angina, or a combination of these. If left untreated, the life expectancy of patients reduces significantly. For instance, it would be a $50 \%$ reduction over a period of 5 years for angina, over a period of 3 years for syncope, and over a period of 2 years for congestive heart failure. Also, these diseases in a small percentage of patients may cause sudden death. Aortic insufficiency has a slower progress rate than the aortic stenosis as it can normally be diagnosed by fatigue symptoms. In some cases, it can be diagnosed by the slow development of congestive heart failure, and in these patients typically angina pectoris and syncope don't occur often. In order to diagnose these diseases, normally echocardiography is implemented to assess ventricular function, the severity of stenosis, and insufficiency. Also, cardiac catheterization is performed to evaluate cardiac output and estimate aortic valve area. An image-based method can be implemented in the coronary arteries to check for any major lesions. To predict postoperative prosthetic valve infection, a precise dental or oral examination is usually performed [1-5].

There are a number of options for repairing or replacing the diseased valves. Although surgery is a common solution, there are novel non-surgical procedures under developed nowadays. Some available surgical techniques include [2-7]:

- A commissurotomy surgery is applied to diseased valves with thickened and fused leaflets. This surgery, known as valvuloplasty or valvular reconstructing procedure, is done by cutting the spots in which the cusps are stuck together.

- In some other cases, if the issue is with the annulus, the required surgery is called annuloplasty. In this surgery, sutures are sewn around a circle so that the opening becomes smaller. In more severe cases, a well-designed 
Mohammadi et al. Cardiovascular System 2017,

ring (known as an annuloplasty ring) holds the original geometry of the healthy annulus. It is applied to reconstruct the annulus back to its original shape. The annuloplasty ring provides more mechanical support to the valve so it can function more effectively. A surgeon may reconstruct a valve by removing some abnormal segments (such as fatty bulges or calcified nodules) off the diseased cusps and sewing it back together.

- If the issue is with the deposition of calcium on the valve tissue, decalcification surgery is applied and calcium buildups from the leaflets are removed.

- The Mitral and tricuspid valves are supported by cords, known as chordae tendineae, and papillary muscles. If the issue with the diseased valve has to do with the cords, i.e., stretched or weakened cords, which may lead to the valve ineffectiveness, the surgery required would replace or shorten the cords.

- If there are holes or tears in the cusps, a tissue patch may be applied.

There are fairly new techniques (to be discussed later) where the surgical process is done but with much less damage on patients. These approaches are collectively known as minimally invasive surgery (MIS). In MIS, surgeons monitor the heart using an appropriate imaging technique and operate using a new class of surgical tools inserted through small incisions. Minimally invasive valve repair is a developing technique that is also known as endoscopic or robotic heart surgery [18].

Furthermore, there areother techniques under development highly regarded asreplacements to conventional surgeries, known as non-surgical therapy. These techniques are called percutaneous or catheter-based surgeries thatdo not require any chest incisions and patients do not need the heart-lung machine during the procedure. $A$ thin elastic tube (known as a catheter) is inserted into the body through a blood vessel and is then directed tothe intended destination in the heart. Percutaneous or balloon valvuloplasty is applied in patients with calcifies or stenosed valves, which is more common for the mitral valve than the aortic valve. An inflatable balloon tip on the end of the catheter is situated in the stenosed valve and inflated to expand the opening,completely crushing the calcified tissue.

For the mitral valve, multiple methods of percutaneous valve repair are in the development phase. If the gap between the anterior and the posterior leaflets is large, it can be repaired using a technique known as edge-to-edge repair. In this surgery, a delivery catheter equipped with a clip is sent through the femoral vein from the groin into the left part of the heart. The clip is situated beyond the diseased valve in an open location and then pulled back so that it hooks the leaflets. Once closed, the leaflets are held together and the valve leakage is fixed [27-33].

If repair is not sufficient for the patient, then replacement could be an option. Replacement is more generally applied for the treatment of aortic valves or extensively damaged mitral valves. In general, there are two types of valves that are considered for valve replacement:

(1) Mechanical valves must be made up of durable biomaterials such as metals, carbon, ceramics and polymers. A sewing ring wrapped with a biomaterial is used to attach the valve to the tissues in the patient's heart. The major advantage is durability. However, anticoagulant therapy (blood diluter) must be taken the rest of the patient's life to prevent thromboembolism (blood clots).

(2) Biological or tissue valves (known as xenograph) which are made up of animal tissue such as pig (known as porcine valves) valve or a pericardial tissue of cow (known as bovine valves).

(3) Human tissues donated from a cadaver (known as allograft or homograft) are also an option.

(4) The replacement can be harvested from patient's own tissues (known as autograft), which is through a surgery known as the Ross procedure (also called switch procedure). In this surgery, the valve is taken from the patient's normally functioning pulmonary valve and is replaces the diseased aortic valve. The pulmonary valve is then replaced with a prosthetic valve, such as homograft or porcine valve. Biological valves are not mechanically efficient and have durability issues, unlike mechanical valves, and need to be replaced every 10 to 15 years. Also, anticoagulant therapy may be needed for these patients for a short duration. Bioprosthetic valves are mostly recommended for young patients, while mechanical valves are recommended for the elderly. This is mainly because older patients may not be able to afford a new open heart surgery [45-51].

\section{Indication for replacement surgery}

Heart valve replacement was first initiated in the early 1960s and is now a normal surgical procedure. It employs devices made of nonliving, nonresorbable biomaterials for used to substitute the valvular mechanical functions. Replacement of heart valves offers a large improvement in the quality of life for thousands of patients and can be considered one of the major accomplishments of biomedical engineering. It is estimated that more than 280,000 replacement heart valves are implanted annually worldwide, makingthe social and economic impact of heart valveresearch and development considerable [1-5].

There is no assurance that a surgical procedure or medical treatment canprevent or defer valve disease. Procedures such as balloon valvotomy could be applied as a bridge to surgery, with a temporary relief of symptoms beingprovided. Patients with symptomatic severe aortic stenosis, who may also have undergoneother cardiac procedures like coronary artery bypass graft surgery, have a poor prognosis and are considered for aortic valve replacement. The severity of aortic stenosis is assessed by diagnostic physical measurements, where the effective orifice area (EOA), the hemodynamic features such as jet velocity, turbulence, the ejection fraction and the 
transvalvular pressure drop are evaluated. EOA is generally measured by the Gorlin formula as follows: Orifice Area $=\mathrm{CO} /$ (HR.SEP. 44.3C. SQR(deltaP) where CO is the cardiac output, $\mathrm{HR}$ is the heart rate, and SEP is systolic ejection period. 44.3C is a constant thatis assumed to be 0.1 for the aortic valve. In this formula,the unit of time is $\mathrm{min}$, the unit of length is $\mathrm{cm}$, delta $\mathrm{P}$ is the pressure drop across the valve with the unit of $\mathrm{mmHg}$ [21-32].

Mechanical heart valves are used to replace diseased human heart valves in approximately $50 \%$ of cases. Bioprosthetic heart valves are used in the other $45 \%$ of cases. Pulmonary autograft valves and human cryopreserved homograft valves represent the remainder of implanted valves. Autografts and homografts exhibit excellent durability after implantation, but are not readily available for all patients.

\section{Mechanical Heart Valves}

Mechanical heart valves (MHV) are artificial valves made of synthetic biomaterials that are developed to replace diseased valves.They are designed to provide the same function as the natural valves of the human heart. This is applicable to the four human cardiac valves: tricuspid, pulmonic, mitral, and aortic valves, as discussed in the previous chapter. The main function of the prosthetic valves is to preserve unidirectional forward flow, which in turn regulates the flow of the oxygenated and deoxygenated blood through the systemic and pulmonary systems. These systems are connected to the heart by the vena cava veins, pulmonary artery, pulmonary vein, and the aorta. Numerous cardiac valve disease processes, (explained briefly in the previous chapter) of both acquired and congenital causes, may lead to one of the four heart valves diseases. They are in the form of stenosis, known as obstructed forward flow, and/ or increased backward flow, known as regurgitation/dynamic backflow. Each of the mentioned conditions would burden the heart with extra work andwould lead to serious complications in the patients, such as heart failure [1].

In general, the durability of mechanical heart valves is long enough that the patient would not need another open heart and/or valve replacement surgeries. The issue with mechanical valves is that the patient would need to take anticoagulation therapy for the rest of their life. The main types of mechanical heart valves are considered as follows: (1) The ball and cage valves, (2) Disc and cage valves, (3) Tilting disc valves, (4) Bileaflet valves, (5) Polymeric valves and (6) Percutaneous valves.

\section{Ball and Cage or Caged Ball Valves}

The first open heart surgery to repair a stenotic aortic valve took place in 1912. In this procedure, the aortic root wall was invaginated with a finger and the aorta was pushed through the valve. The next registered open heart surgery took place in 1914, which was about the dilation of a calcified aortic valve. This was achieved with apparatuses passed from the innominate artery or another arterial source [87].
Advent of caged ball valves was a major innovation in the treatment of patients with valvular heart disease. The place of caged ball valves in history remains undisturbed, as they continue to serve as a benchmark against which the newer tilting disc and bileaflet designs are evaluated. It is also clear from information in literature that these mechanical valves comewith a number of complications, the majority of which are related to higher pressure drops and poor hemodynamics [87].

In 1952, Dr. Charles Hufnagel, implanted the first ever ball and cage valve, which was named after himself as the Hufnagel's valve (Figure 14). This valve was a unique design of a ball entrapped in a transparent glassy type cage. The ball was made of methacrylate covered by silicon rubber and the cage made of methacrylate. This material was the first implanted in an animal model to test a tube made of methacrylate for arterial replacement in late 1940's. The material for the ball was immediately modified; instead, a hollow nylon ball covered by silicon rubber was implemented. It was thought that a smaller ball with smaller momentum could reduce noise and enhance dynamic behaviour of the valve, such as the regurgitation flow and the impact force between the case and the ball. More than 200 of Hufnagel's valves were implanted for patients with aortic insufficiency [87].

In the early designs of caged ball valves, the issue was with the contact that the ball could make with the aortic wall during the systolic phase, which could lead to hemodynamic complications in those regions. In order to address this issue, the idea was to improve the cage by giving the floating ball a larger, yet controlled space. In this design, a second outer concentric cagethat slightly penetrates the left ventricle chamber was added to the valve. This model was implanted

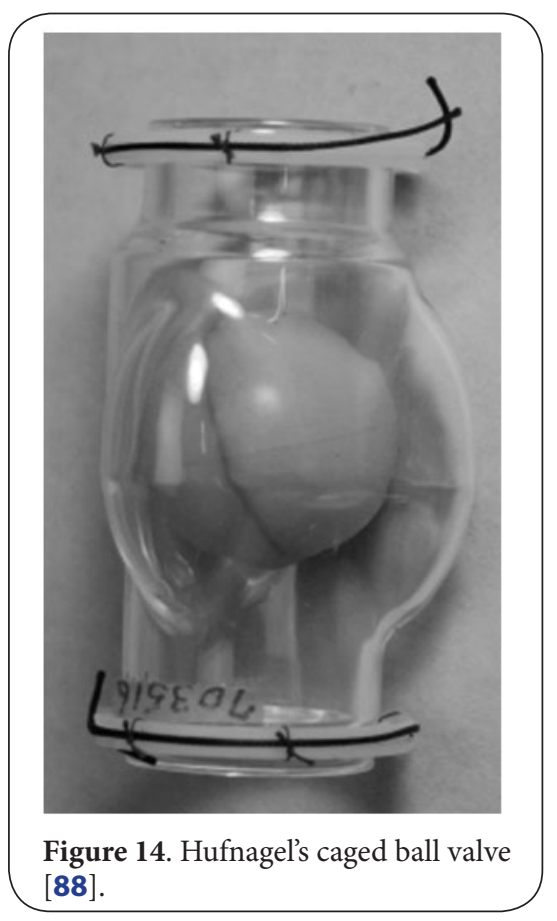


in 7 patients, two of which survived. The patients that survived needed following valve replacements, one for a perivalvular leak after 3 years and one for bacterial endocarditis after 22 years. In these models, the ball (which was made of silicon) showed excellent structural integrity as it had not deteriorated after 22 years implantation [89].

The next model of the the ball and cage valve was designed by M. Lowell Edwards, a retired engineer, and Dr. Albert Starr, a young cardiac surgeon, in the early 1960's. The valve was commercially branded as the Edwards-Starr ball and cage valve. It was a bulky valve (Figure 15) where the ball was made of elastomer rubber and the cage was made of methacrylate. These were also known as Lucite (methacrylate) valves. This valve was implanted in a 50 years old patient who was diagnosed with calcific mitral stenosis and the patient survived for several years. There was animmediate improvement on the Lucite valves byswitching from methacrylate to stellite metal for the cage [89].

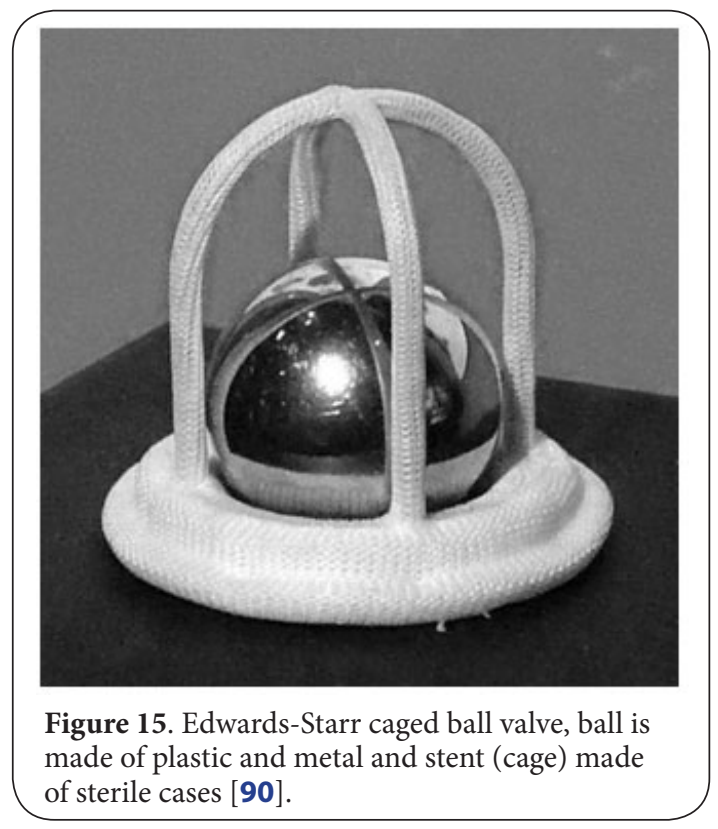

In the Edwards' laboratory, several ball and cage models were developed for both the aortic and mitral positions over almost 10 years. A number of models of Edwards-Starr valves were commercialized and named as the Edwards-Starr 1000, 1200, $1250,2300,2400$, etc. Model 1000 was developed for the aortic position in the early 1960's. In the 1200 model, the cage was made of heavy stellite, the annulus covered by Teflon fabric, and the ball a hollow stellite ball. The silicon rubber ball was no longerused because lipids could be absorbed, leading to fast deterioration. In the model 1250 , the ball was made of hollow stellite, and was little different from model 1200 . The issue with models 1200 and 1250 was that they were noisy. Model 2300 was developed in 1967 where whole stent was covered by cloth. This could control the noise issue to some extent; however, the new issue was that the fabric could be damaged by the stellite ball. Model 2400 , also known as the track valve, was developed for the aortic position in 1972 and the covering fabric of the stent was eliminated. There were other Edwards-Starr Models thatwere developed for the aortic position, such as model 1260 , and for the mitral position, such as models 6000 and 6120 . In these models, the cage was fabric free and made of stellite and the ball made of silastic rubber. These models were implanted more than 300,000 times worldwide with almostno issues with the ball due tothe postmold silicone rubber heat cure process. The last models of Edwards-Starr valves contained the stent or strut with no cloth and the ball made of heat-cured silicon elastomer, which lasted until early 2000 [89].

\section{Magovern-Cromie Ball and Cage Valve}

Other ball and cage models were developed as well in the 1960 's. Dr. Magovern, a cardiothoracic surgeon, and Harry Cromie, an engineer,designed a ball and cage valve for the aortic position. It possessed a unique feature for fixation without suturing. Following their names, it was branded as the Magovern-Cromie ball and cage valve. In this model, the ball was made of heat-cured silicon rubber and the cage was made of titanium. For implantation, a rotating tool was designed in order to insert the valve into position and engage it with several vertical pins in the aortic annulus. This model had significant advantage over other available models at the time simply because the implantation process was quick. Thisremovedthe need for the cardiopulmonary bypass, which was not as safe and reliable as it is today. This valve was implanted in aortic position in 7300 patients and in the mitral position in 200 patient till 1988. The issue with this valve was structural defect of the ball after some time, which was reported in $2 \%$ of patients. This was also the main issue with the Edwards-Starr valves, which was addressed properly later with the post-mold heat cure process of the ball (Figure 16-1).

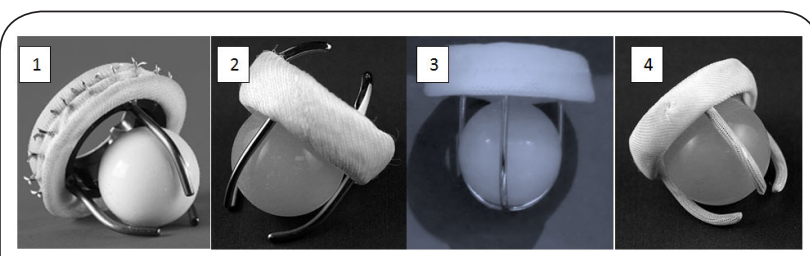

Figure 16. (1) McGovern-Cromie caged ball valve designed in $\sim 1965$, (2) Smeloff-Cutter caged ball valve designed in 1966, (3) Debakey-Surgitool caged ball valve designed in 1969 , and (4) Braunwald-Cutter caged ball valve designed in 1968 [90].

\section{Smeloff-Cutter ball and cage valve}

The next idea for a caged ball valve was to provide a full-flow orifice model, which was commercialized as the Smeloff-Cutter ball and cage valve in 1966. This valve followed the name of Dr. Edward Smeloff, a cardiac surgeon, and the Cutter laboratory at the University of California, Berkeley. In this model, 
two titanium cages were addedon each side of the valve and the ball was made of heat-cured silastic. The effective design of the cage allowed the silicon ball to sit on the smaller cage in the closing phase. This valve was implanted in $\sim 72,000$ patients in both aortic and mitral positions (Figure 16-2) [89].

\section{Debakey-Surgitool ball and cage valve}

Dr. DeBakey and Harry Cromie of Surgitool proposed a new design for a ball and cage valve, commercialized as DebakeySurgitool caged ball valve in 1967. In this design, the cage was made of titanium and the ball was made of high molecular weight polyethylene instead of heat-cured silicon rubber. However, the material for the ball was soon changed to a hollow pyrolytic carbon ball. This was the first ever valve in which a new carbon-based material was implemented. The idea was to improve the quality of the ball to be more resistant against any structural defects. However, to some degree hard the ball and soft titanium cage caused structural defects and rapid wear rate in the cage.Strut and cage fracture was reported in multiple occasions (Figure 16-3). [89].

\section{Braunwald-Cutter ball and cage valve}

Drs. Braunwald and Morrow proposed a new model of ball and cage valve wherethe cage was made of titanium and the ball was made of silicon rubber. In this model, the cage and annulus werecovered by a flexible polyurethane-Dacron fabric. This valve was used in the mitral position with attached Teflonropefor chordae tendoneae. Later on, it was observed that the fabricwas penetrated by fibrous connective tissue,leading to the idea that covering the titanium cage with the ball and cage valve fabric might decrease thrombus formation (Figure 16-4).

The development of the cloth for covering the cage was continued. In a new design, the cagewas covered with knit Dacron tubes and the inflow ring with an ultrathin polypropylene mesh fabric, which led to low incidences of valve-related problems. However, the main issue with this model was with the fabric. As itwas not mechanically stable, fabric wear and silicon ball structural defect were reported frequently.

\section{Disc and Cage Valves}

From an engineering standpoint, it makes sense if the ball in the traditional ball and cage valve was replaced by a disc. For a heart valve, a lighter and more agile disc could be more effective (e.g., quicker dynamic response) than a heavy ball. This is because dynamic stresses on the occluder (disc or ball) and the cage could be reduced, the regurgitation flow could be lessened, and the overall dimensions of the valve could be much smaller with a disc. The main question; however, was if disc and cage valves could offer a better hemodynamic performancethan ball and cage valves.

\section{Kay-Shiley Disc and Cage Valve}

Dr. James Kay a professor of cardiac surgery, and Donald Shiley, an engineer, proposed the first ever design of a disc and cage valve in 1965. This design was for the mitral position with the cage made of stellite and the ball made of silastic. The wear was still a major issue with the disc in this model,and shortly after in 1975 the material used for disc was modified to Derlin. This model was implanted in 12,000 patients until 1980 when the manufacturing of these valves was stopped. The Kay-Shiley disc and cage valve was probably one of the most widely used mitral valve prostheses from 1965 to 1980. Later on, Dr. Kay improved the design of his valve by adding a muscle-guard in order to prevent disc impingement. This model was never marketed and was never used by any other surgeons other than himself [89].

\section{Beall-Surgitool Disc and Cage Valve}

In 1971, Dr. Arthur Beall, a cardiologist, and Mr. Howard Cromie of Surgitool designed a disc and cage valve where the disc was fairly flat and made of Teflonwiththe cage made of Titanium. A few design modifications were implemented on this model such as: (1)a velour fabric was used to cover the annular apron, (2) the Teflon disc was replaced by Pyrolyte, etc. This model was implanted in nearly 5,000 patients in the aortic position until 1985. The production of this model was stopped mainly due tofabric wear on the annular apron.

\section{Cooley-Cutter biconical disc and cage valve}

Similar to a biconical ball and cage valve, a biconical disc and cage was proposed by Dr. Denton Cooley, a cardiac surgeon, and his engineering colleagues at the Cutter laboratory in late 1960's, In this model, the disc was made of Titanium and the cage was biconical and made of Pyrolyte. This model was conceptually very similar to the Smeloff-Cutter valvewherefullflow orificewas achievable due to a double strut cage. This valve was implanted in nearly 3000 patients in both the mitral and the aortic positions.

The major advantage of the caged ball and cageddisk valves over others isthat theymaintain a very simple design. In fact, in these models, the onlymoving part is a ball or a disc in the most simplistic way. The major drawback of these valves, however, is that they have a poor hemodynamic performance. As theblood must flow around the ball, this lead to a higher pressure drop across the valve and caused the heart to perform extra work. The disc cage valve is much worse than the ball and cage valves, which makes these valve have a higher rate of thromboembolism (Figure 17).

\section{Tilting Disc Valves}

From an engineering standpoint, if the motion of the disc in a disc and cage valve could be controlled by a mechanism, it follows that the hemodynamics of the valve may improve significantly. One of the obvious disadvantages of the design of the disc and cage valve is the high pressure-drop across the disc. Also, the blood flow is easily disturbed due to the geometry of the disc,which may lead to turbulent flow downstream of the valve. This disadvantage can be addressed to 


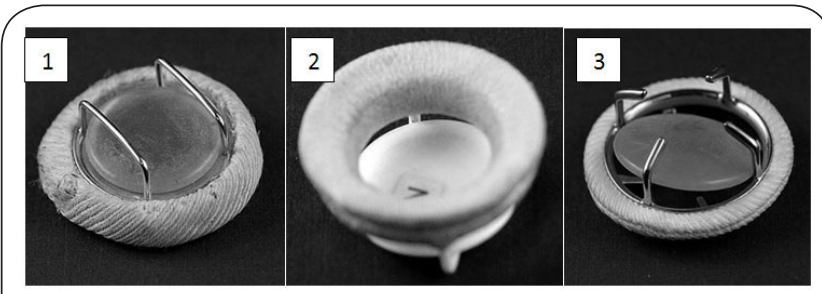

Figure 17. (1) Kay-Shileycaged disk valve designed in 1966, (2) Beall-Surgitool caged disk valve designed in 1974, and (3) Cooley-Cuttercaged disk valve designed in 1974 [90,91].

some point by improving the design of the cage and disc valve by replacingthe floating disc with a tilting disc.

\section{Bjork-Shiley Flat Disc Valve}

in 1960, Dr. Viking Bjork, a cardiac surgeon, and Donald Shiley, an engineer,proposed the first tilting disc valve. In this model, the disc was made of Derlin polymer, and instead of a cage, they designed a strut. The strut was made of stellite, which was intended to control the motion of the disc in both the opening and closing phases. This model was considered for both the aortic and the mitral positions and was implanted in almost 300,000 patients until 1986. Derlin polymer was not an appropriate biomaterial for this application because it absorbs water, which can cause defects in the structure of the disc. In the later models of this valve, the material for the disc was changed to Pyrolyte in order to address this issue.

\section{Bjork-Shiley Convexo-Concave Tilting Disc Valve}

In 1975, the geometry of the strut and the disc in the flat disk Bjork-Shiley valve was significantly improved in order to provide a better hemodynamic performance. In this model, the two struts (inlet strut and outlet strut) were made of stellite and the disc was made of Pyrolyte. The struts were welded to the annulus. The idea was to design a 3D structure for the strut to allow the disc to slide forward and downward by approximately $2 \mathrm{~mm}$ more, compared to the standard Bjork-Shiley model. Also, the disc was no longer flat as it was replaced by a convexo-concavedisc. This model improved the hemodynamics of the Bjork-Shiley valve significantly and was implanted in almost 85,000 patients in both the aortic and mitral positions. The main issue with this valve was the fracture of the struts, and in particular, the outlet strut. This malfunction was reported in almost $2 \%$ of the patients. Due to this issue, the manufacturing of this model stopped in 1986. It should be noted that a mono-strut tilting disc Bjork-Shiley valve,whereonly one strut is attached to the annulus without welding, was implanted in more than 100,000 patients with no structural failure reports (Figure 18).

\section{Lillehei-Kaster Tilting Disc Valve}

In 1970, Dr. C. Walton Lillehei, a cardiac surgeon, and Ms. Robert Kaster, an engineer, designed a new tilting disc valve named the Lillehei-Kaster tilting disc valve. In this model, the

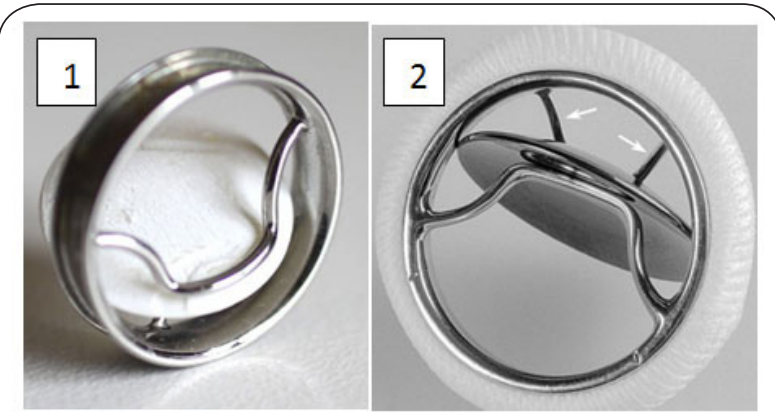

Figure 18. (1) Bjork-Shiley flat disk valve designed in 1960, (2) Bjork-Shiley convexo-concave tilting disc valve designed in 1975 [90,91].

disc was made of Pyrolyte and the strut was made of Titanium. The major feature of this model was the design of the strut wherethe motion of the flat disc of valve wasregulated by two protuberant side-prongs. This model was successful to some extent and was implanted in almost 55,000 patients in both the aortic and the mitral positions. The fabrication of this valve was stopped in 1976 simply because it was replaced by the consecutive models, the Omniscience tilting disc valves.

\section{Omniscience Tilting Disc Valve}

This model was a modification to the Lillehei-Kaster tilting disc valve by Robert Kaster where the profile of the protuberant prongs on the annulus was improved. Also, the disc of the Lillehei-Kaster valve was no longer flat. A slight curvilinear profile in the Omniscience valve was incorporated to the disc. In this model, the strut was made of Titanium and the disc was made of Pyrolyte. This model has been implanted in almost 75,000 patients in the aortic position and in nearly 25,000 patients in the mitral position. The major feature of this model compared to other available tilting disc valves was its curvilinear disc.

\section{Omnicarbon Tilting Disc Valve}

The Omnicarbon and Omniscience valves were designed and manufactured around the same time. The major advantage of the Omnicarbon over Omniscience was the material used for the strut, which was Pyrolyte rather than Titanium. The other design features were basically identical. These two models were very successful, possessing outstanding durability and structural integrity properties.

\section{Hall-Kaster and Medtronic-Hall Tilting Disc Valves}

In 1977, Robert Kaster and Dr. Karl Victor Hall, a cardiac surgeon, designed a new tilting valve which was named first as the Hall-Kaster and later as the Medtronic-Hall tilting disc valves. In this model, the strut plays the role of thedisc's guide. In the centre of the disc, there is a hole through which the guide is passed. The strut is made of Titanium and the disc is made of Pyrolyte. This model was implanted in almost 190,000 patients in the aortic position and in nearly 125,000 patients in the 
mitral position with no structural failure reports. There are still some hospitals in the world where this model is implanted in patients (Figure 19).

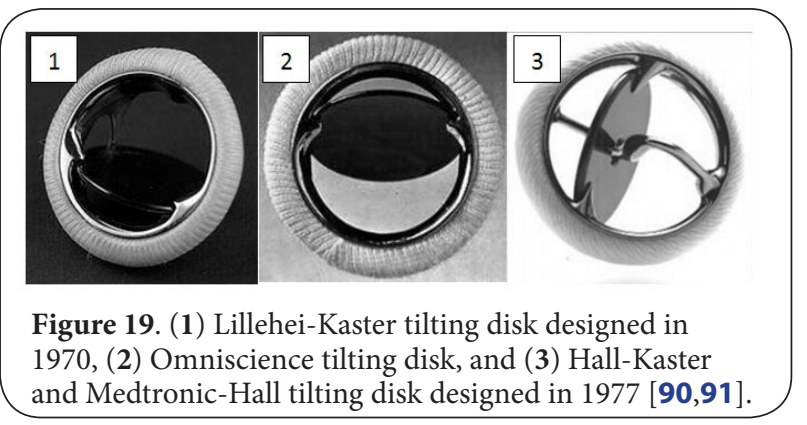

From an engineering perspective, if the disc in a disc and cage valve is broken down into two pieces, each engaged within the ring by hinges, this could provide a central blood stream through the valve. In fact, the hemodynamics in bileaflet valves must be better compared to previous models, as listed: ball and cage valves, disc and cage valves, and tilting disc valves. This is simply because the central area of the valve, where the velocity of blood could be maximum, is wide open to the blood flow. The bileaflet concept, a hinge mechanism, and a low profile are some of the basic design features of bileaflet heart valve prosthesis. They have two semicircular leaflets engaged within the ring by hinges. The leaflet hinge is located at the center of the valve annulus, and leaflets open and close similar to a butterfly's wings. The relation between the leaflet motion and the flow through the valve is: (1) Leaflets open rapidly when the forward flow starts, (2) around peak flow, the leaflets remain stable at the maximumopening position, and (3) leaflets maintain the opening position while the flow rate decreases slowly after the peak flow. Leaflets are still in the open position as the flow rate drops to almost zero. Finally, the leaflets start to close when backflow happens. Bileaflet valves are the most protected as the leaflets hardly protrude from the valve ring, even during maximum opening.

\section{Gott-Daggett Bileaflet Valve}

In 1969, the application of a hollow ball made of Pyrolyte (also known as pyrolytic carbon) in a ball and cage valve (used in the DeBakey-Surgitool valve) was a further evolution in the design of mechanical valves. Drs. Vincent L Gott and Ronald Daggett, a professor of polymer engineering, designed the Gott-Daggett bileaflet valve in 1963. In this model, the housing (annulus) was made of carbon coated Lexanand the leaflets were made of silicon coated Teflon fabric. In fact, the valve was flexible, and was branded as the Gott-Daggett bileaflet valve. The housing also had a graphite-benzalkonium-heparin coating,making this the first ever prosthetic valve with carbon coating. Dr. Bokros, who was the initiator of this idea, suggested that binding of heparin andPyrolyte could offer excellent blood compatibility properties. However, the issue was that a well-polished Pyrolyte surface and heparin will not bind. Nowadays, it is well established that the Bokros material was the most blood compatible material (thrombo resistant, nonheparinized material) that had been developed until that point. This material was applied to the ball in the DeBakey-Surgitoolball and valve model.This was the model he was focused on previously. This model was implanted in almost 300 patients in the aortic position and in 200 patients in the mitral position with fairly good clinical results. This model, however, had a major drawback. There was rather stagnant blood flow in the region of the super-strut implemented to capture the flexible leaflets. This region was often the location of thrombus; however, no clinical episodes of thromboembolism were observed.

\section{Kalke-Lillehei Bileaflet Valve}

In 1964, Drs. Bhagabant Kalke and C. Walton Lillehei proposed a new design for mechanical heart valves. They came up with the first ever design of bileaflet mechanical valves with a pivot mechanism. They designed a bileaflet mechanical valve in which the pivot sites for the two solid leaflets were located at the equator of the housing or annulus. In their initial model, they used an overriding semicircular strut/brace to avoid leaflet escapement. Later on, after Dr. Kalke joined Dr. Lillehei's laboratory, together they proposed a design wherea pivot mechanism for the two leaflets was considered (first ever design of the pivot mechanism) so that the overriding strut/bracewas no longer necessary. Only a few of these KalkeLillehei valves were fabricated and only one was implanted in a patient who died after 48 hours in 1968. The cause of death was advanced rheumatic mitral disease, so the fabrication of the Kalke-Lillehei valves wasstopped mainly because of the lack of an appropriate biomaterial for this model.

\section{St. Jude Medical Bileaflet Valves}

The design of the St. Jude Medical bileaflet valve was conceptually similar to the design of the Kalke-Lillehei valve and was first introduced in 1977. In the design of the St. Jude valve, however, the focus was more on the improvement of the pivot hinge. In this model, both the leaflets and the housing were made of Pyrolyte, which made the St. Jude valve the first ever valve made entirely of carbon. Xinon Posis, an engineer, proposed the first design of a St. Jude valve in 1976 wherethe pivots werenear the periphery, providing a central opening. Xinon Posis, with Dr. Demetre Nicoloff, a cardiac surgeon, and Donald Hunson, an engineer, redesigned the St. Jude Medical valve multiple times. The focus was mostly on a modification of the hinge design. Posis, Jack Bokros, the initiator of the idea of using carbon in valve construction, and Hanson improved the design of the hinge and introduced the new concept of a leaflet-tab spinning in a butterfly-recessinsideof the housing wall. The design of this model was a success and soon became a major alternative for the replacement of the diseased valves. This valve has been implanted millions of times in patients in 
Mohammadi et al. Cardiovascular System 2017,

http://www.hoajonline.com/journals/pdf/2052-4358-5-2.pdf

doi: $10.7243 / 2052-4358-5-2$

both the aortic and the mitral positions.

\section{Carbomedics bileaflet valves}

In 1986, Dr Bokros designed a similar valve to the St. Jude where was made of Pyrolyte both the leaflets and the housing were made of Pyrolyte. In this model, the main feature was the housing that could rotate with respect to the sewing ring. This valve was marketed as the Carbomedics bileaflet valve and was implanted in more than 350,000 patients in the aortic position and in 250,000 patients in the mitral position.

\section{On-X bileaflet valves}

Dr. Bokros introduced a new design for bileaflet mechanical heart valves in 1996. This model was an overall improvement on St. Jude medical bileaflet valves and was branded as the On-X valve. The surfaces of the leaflets and the housing were coated with pure carbon and extremely polished to provide high quality surface properties. In the On-X valves, silicon had been completely removed from its structure, unlike conventional models. This is because silicone embedded carbon may lead to a low surface quality, which in turn increases chance of blood damage near the surfaces of the leaflets and housing. That was the case in the regions close to the hinges. The most significant design feature of this model was that itaddressed insufficient hemodynamics in small aortas. Periodic incidents ofhemolytic anemia, extreme pannus overgrowth or tissue interference, and thrombogenic complications are the issues associated with hemodynamics of bileaflet mechanical valves, especially in small sizes. Low profile valves (low length to diameter ratio) are prone to tissue ingrowth (pannus). The profile (length to diameter ratio) of the On- $X$ valve is designed to be similar to that of thenative aortic valve,therefore providing unique protection from tissue damages on both the inflow and outflow sides. An inlet flare, full annulus support, and leaflet guards are allcomponents in the design. The opening angle is considered to be $90^{\circ}\left(>80^{\circ}\right.$ in SJM), which is thought to improve the hemodynamics of the valve significantly. The design of the pivot hinge is also improved, which may in turn lead to more stability of the hinges and less thromboembolic complications. Pivots are high potential sites of clot formation, due to the possibility of flow stagnation (stasis). In the On-X design, the location and the geometry of the hinges were designed so they are being constantly washed out in every cardiac cycle more efficiently compared to conventional valves. This is done to eliminate possible flow stagnant regions around the hinges. The backflow channels are sensibly designed in order toavoid hemolysis by allowing blood flow to penetrate the pivot areas. The improved hemodynamics provided in the $\mathrm{On}-\mathrm{X}$ valve is thought to decreasethe anticoagulation therapy in low-riskpatients. This valve has been implanted in so many patients so far in both the aortic and the mitral positions and together with St. Jude Medical valve are the most widespread prosthetic valves alternative considered by cardiac surgeons globally.

\section{ATS Bileaflet Valves}

The ATS bileaflet valve, similar to the St. Jude medical valve, was a new design of bileaflet heart valve that was made of Pyrolyte in 1994. This model was branded as the ATS Open Pivot valve prosthesis. The main feature of the ATS prosthesis was the design of the hinge,where a ball hinge was proposedinstead of a cavity hinge. Since this model's pivot areas are fully exposed to the blood stream, the hinge area can be washed out effectively. The sewing cuff is attachedto a titanium ring in a way a rotation during implantation. Radiopacity is also provided, which is helpful for visualization by roentgenography. The radiopacity is possible in this model because of the presence of $20 \%$ tungsten in the leaflet construction. The ATS bileaflet valve is thought to provide a better hemodynamics and less noise compared to other bileaflet valves. The ATS bileaflet valve has been implanted in nearly 1200 patients in both the aortic and the mitral positions from 1994 to 2000 (Figure 20).

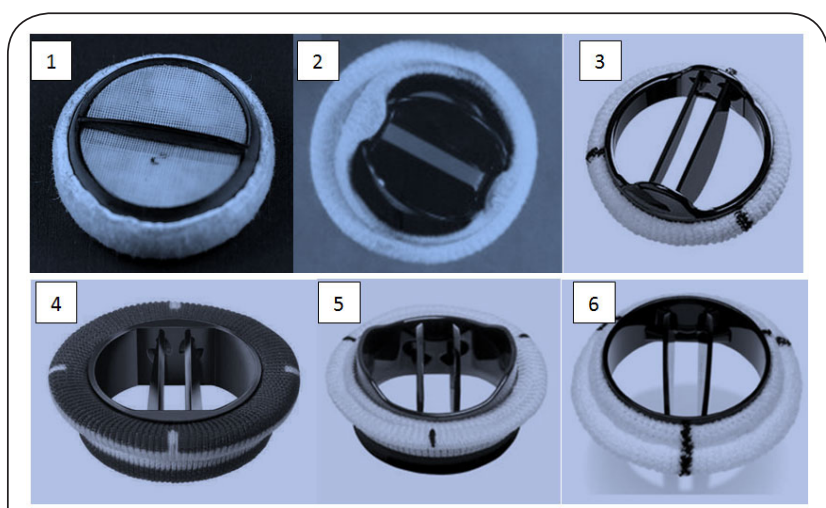

Figure 20. (1) Gott-Daggett bileaflet valve designed in 1969, (2) Kalke-Lillehei bileaflet valve designed in 1964, (3) St. Jude Medical valves designed in 1977, (4) Carbomedics valves designed in 1986, (5), On-X valve designed in 1994, and (6) ATS valve designed in 1994 [90,91].

\section{Sorin Bileaflet Valves}

The idea behind the Sorin bileaflet valves was to design and fabricate an advanced version of the original bileaflet model, which would overcome some of its inherent deficiencies and surpass its performance. In order to improve the bileaflet valves available at the end of the penultimate decade of the last century, Sorin Biomedica (Saluggia, Italy) focused on three main points: hemocompatibility (minimal damage to blood components and prevention of thrombotic deposits); hemodynamics (low resistance flow pattern similar to that in natural valves); and durability. Experience with the Sorin tilting disc valve clearly indicated that the most biocompatible material for blood contacting surfaces is pyrolytic carbon, whether it is solid or used as a coating. Maximal hemodynamic performance was achievedwith the design of the curved leaflets and the aerofoil inner housing profile. Structural stability and excellent mechanics resulted from the choice of a titanium 
alloy for the housing when combined with the decreased thrombogenicity of the pyrolitic carbon coating. The hinge design was based on the principle of rolling without sliding. Consequently, uninterrupted washing of the hinge surfaces is achieved at each point of the cardiac cycle with controlled blood leakage. The housing is rotatable within the sewing ring. Short-term results were reported by Casselman and Goldsmith, andintermediate results were subsequently presented in a large cohort of 1350 patients.

\section{Elliptic St. Jude Medical Valves}

In 2014, the Heart Valve Performance laboratory at the University of British Columbia (the authors) published a manuscript in the Journal of Biomechanics. They suggested a new design for the stent (housing) of SJM valves in which $15 \%$ ovality was applied to the stent whileits perimeter remains constant. In a pilot study, the hemodynamic performance of the proposed design was analyzed in the closing phase and then compared to that of conventional SJM models. Results showed that while the elliptic SJM model offers a shorter closing phase $(9.7 \%$ shorter), the regurgitation flow remains almost unchanged. In other words, even though the dynamic response of the valve improved, the regurgitation flow did not decrease. Thus, a more efficient and effective orifice area (EOA) was provided by the proposed model. The elliptic concept can be applied to the On-X valve as well and improved hemodynamics are expected in the elliptic On-X valve compared to the conventional On-X models (Figure 21).

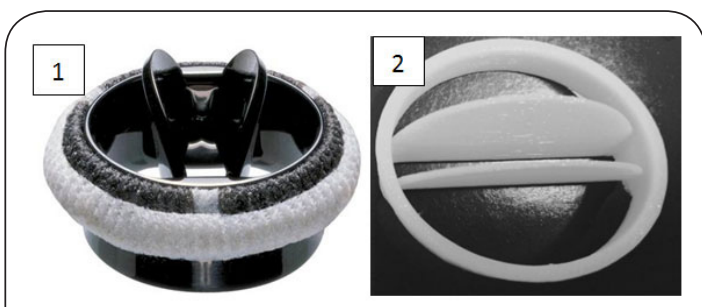

Figure 21. (1) Sorin bileaflet valves [90,91], and (2) the elliptic St. Jude Medical valve designed in 2014.

Tissue Valves or Bioprosthetic Heart Valves (BHVs) Bioprosthetic heart valves, which are also known as tissue valves, are the prostheses made entirely of animal or human tissues. BHVs are divided into 3 groups: xenograft, allograft and autograft. Xenograts are those made of animal tissues. Two candidate animals, pigs and cows, are commonly used for bioprosthetic aortic valves. Xenograft valves harvested from pigs are known as porcine, and those harvested from cows are known as bovine valves. Porcine valves are basically the aortic valve harvested from pigs and have similar structure to that of humans. This is simply because several components of the cardiovascular system in pigs, such as the heart structure, systemic pressure, aortic heart valve, mitral valve, and aortic root is similar to those of humans. Bovine valves are made of the precordium tissue harvested from cows. In fact, only the leaflets are made of pericardium, which will be attached later on to a synthetic stent. In terms of the design procedure, porcine valves are one step ahead of bovines, simply because porcine valves are already a valve, whereas bovine valves should be designed and fabricated in a form of a valve. Allografts are those harvested from cadaver. They are excellent alternatives for bioprosthetic valves, but are not readily available at the right size and time when needed. Autogratfs are harvested from a patient's own body, in which the patient's pulmonary valve is moved to the aortic position through the Ross Procedure. The Ross procedure, also known as a pulmonary autograft, is a cardiac surgery in which a diseased aortic valve is substituted with the patient's own pulmonary valve. A pulmonary allograft or any other prosthetic valve is then used as the patient's pulmonary valve. This operation is more often recommended in infants and children, but is not uncommon in adults as well.

The arrival of tissue valves is associated with the introduction of glutaraldehyde for the fixation of biological tissue by Dr. Carpentier in 1969. The tissue treatment with glutaraldehyde is essential for the design and fabrication of bioprosthetic valves, including porcine and bovine pericardium valves, which are made of animal tissues. The main issue with the animal tissues used in the structure of prosthetic valves is the potential of thrombogenic complications. In 1970, the Hancock standard porcine BHV was implanted in the aortic position. After a while, the Hancock modified orifice (MO) BHV was introduced in order to addressthe high post-implantation gradients associated with small-size valves in the aortic position. The issue was due to the bulky muscle under the right coronary leaflet. In this model, a composite valve is designed where the right coronary leaflet is replaced with a leaflet from another valve,with the muscle bar already removed. After this model, the Carpentier-Edwards standard porcine BHV was introduced in 1975. The consecutive generationsof BHVsconsist of the Carpentier-Edwards supraannular (SAV) porcine model, which was introduced in 1981; the Hancock II porcine model, which has been available since 1982; and the Medtronic intact porcine model, which was introduced in 1985. These BHV models are known to offer improved zero-pressure fixation that maintainsdelicate but significant histologic features of the valve leaflets, along with anti-mineralization treatments to decreasecalcification-oriented deterioration of the valve tissue. The idea is to provide the new designs with a more flexible, lower-profile stent and smaller sewing rings,which can essentially lead to a larger orifice area.

The first bovine BHV model was the lonescu-Shiley valve introduced in 1971.10 years later, the first improvement on that model was made, and a low-profile model was designed where the rate of failure was much higher. On the $2^{\text {nd }}$ attempt on that model, a final model III was developed and implemented clinically. This was before the Shiley model was withdrawn off the market, and the production of pericardial valves was officially terminated in 1977 . The Mitroflow pericar- 
Mohammadi et al. Cardiovascular System 2017,

http://www.hoajonline.com/journals/pdf/2052-4358-5-2.pdf

doi: $10.7243 / 2052-4358-5-2$

dial valve was introduced and first was implanted clinically in 1982. The most commonly used pericardial BHV presently is theCarpentier-Edwards pericardial valve, which was designed and clinically implanted in 1980 . There are modified versions of this valve available on the market, which are known as the Perimount RSR37 and Magna series (Figure 22).

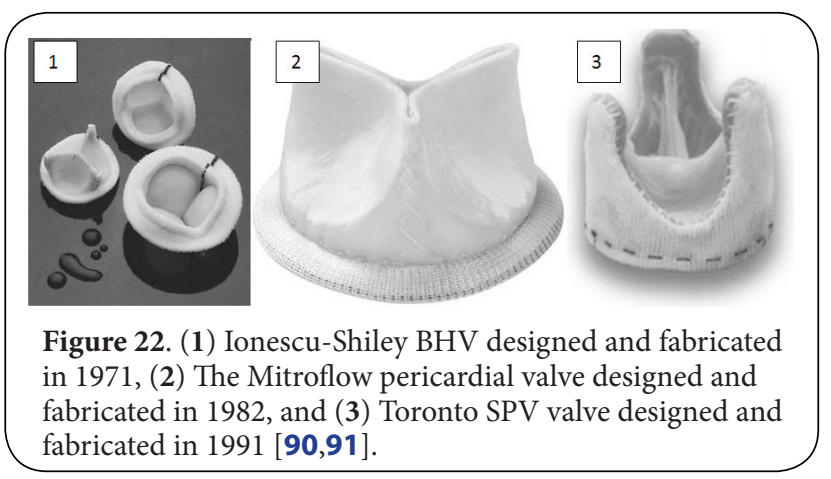

The first clinically approvedBHV stentless model for the aortic position was the Toronto stentless porcine valve,also known as the SPV valve, which wasdesigned and fabricated in 1991. In this design, the available orifice area was significant, which originated in the concept of stentless BHV models. To reach such a remarkable effective orifice area, the sewing ring was minimized and the supporting struts were eliminated. In the design of the SPV valve, a native porcine valve that was reinforced by a small quantity of fabric was considered. The fabric wasthen sewn to the patient's annulus in a planar fashion. Then a small amount of porcine aorta around the valve commissures was implanted straight into the patient's native aorta. to for other conventional stentless BHV models, the Edwards Prima Plus porcine BHV model, the 3F Therapeutics stentless equine BHV model, and the Medtronic Freestyle porcine BHV model are quality considerations.

The first experimental animal studies that includedautograftof the aortic tissue were performed in 1952. In this study, an allograft aortic valve was implanted into the descending aorta of a dog. A few years later, an allograft aortic valve was implanted into the human descending aorta in 1955. The method for subcoronary implantation of allografttissue via the single-suture technique was initiated and applied in 1962 in patients with a freeze-dried aortic valve, a feat implemented shortly afterward byBarrett-Boyes. There have been multiple revolutionary techniques which were used for the sterilization of homograft valves, such as (a) formaldehyde, (b) chlorhexidine, (c) propiolactone, (d) methylene oxide, (e) gamma radiation, and ( $f$ ) storage using a carbon dioxide freezer at $-70^{\circ} \mathrm{C}$. Presently, most homograft valves are (g) cryopreserved with low-dose antibiotics.

Porcine aortic valves or bovine pericardial sheets can be mounted on supports to make a valve with stent, which is to mimic the valvular architecture, or they can be left un-mounted to make a stentless valve (Figure 23).

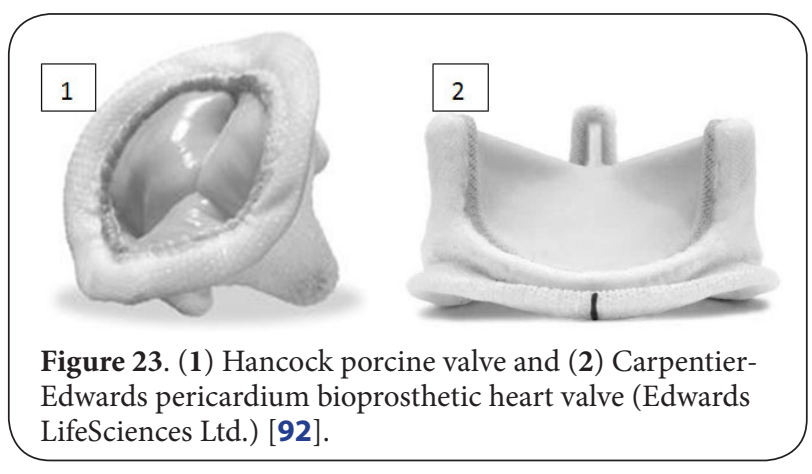

Following the same concept as natural valves, the function of BHVs is pressure-driven. Ifthere is a pressure gradient across the valve (or the blood pressure before the valve becomeslarger than the pressure after), the cusps are forced towards the outside by reversing their curvature. This causes the valve to open. When the blood pressure after the valve becomeslarger than the pressure before, the valve closes by pushing the cusps toward the center. As the total surface area of the cuspsis more than that of the orifice, the two adjacent cusps overlap in the center.This is known as the coaptation area,which plays a major role in complete closure of the valve without leakage or dynamic backflow (regurgitation flow).

The main issue with the BHVs is thatcross-species implantation of animal tissues causes an immune rejection and therefore quick tissue deterioration. For this reason, bovine or porcine valves are treated with glutaraldehyde. Glutaraldehyde is regularly implemented in biomaterialsas an amine-reactive homo-dual-functional cross-linker.For instance, it is used to determine theoligomeric state of proteins. Glutaraldehyde is also implemented in polyacrylamide gel electrophoresis(SDSPAGE) to fix peptides and proteins before staining. In fact, the objective of SDS-PAGE is to distinguish certainproteins based on their size only. Usually, a gel is treated with a $5 \%$ solution for nearly 30 minutes. It is then completely washed to eliminate the yellow stain caused by reacting with free hydroxylmethy laminomethane. In general, a cross-link is a bond between two polymeric chains, including long molecules, etc. This bond may be ionic or covalent, and these polymeric chains may be synthetic, such as rubber, like materials, or natural,such as proteins. The concept of "cross-linking" for proteins typically refers to the use of cross-links to improve the targeted protein's physical properties. In biomaterials, crosslinkingrefers to the use of a concept or method to link proteins together,which is implemented for protein-protein interactions studies.

Glutaraldehyde is a water-soluble cross-linker, which completely decreases tissue antigenicity. Furthermore, glutaraldehyde devitalizes tissues and destroys all existing cells, therefore preventing degradation by host enzymes, and sterilizes the tissue for implantation. BHVs are less thrombogenic than mechanical heart valves and do not need long-term anticoagulation.

In general, BHVs'performancein both hemodynamics and 
structure is excellent for many years after implantation, but their long-term durability is an issue. Clinical reportsshow that more than $50 \%$ of patients with a BHV replacement develop complications within 10 years, which suggests that the majority of implanted BHV valves need to be explanted after 20 years. It is known that a second open-heart surgery to recover and replace the defective valve is prone to high clinical risks, and therefore is not recommended. The absence of longterm valve durability is particularly significant in the case of pediatric patients, where additional surgical procedures are needed to accommodate the natural growth of the patients.

The choice between BHVs and MHVs depends highly on individualpatient features. MHVs are more durable but need life-long anticoagulant therapy, whereasBHVs are prone to deterioration more quickly but do not need anticoagulation therapy. The major reasons for BHV failure are (1) structural destruction and (2) calcification of the tissue constituent. Analysis of failed BHVs naturally discloses the coexistence of structural deteriorationand calcification. Structural failuremay not be associated with calcification, so it can be a purely stress-induced disruption of fiber architecture, or induced by enzymatic deterioration. Mechanical stresses/deformationsof the tissue were thought to effectivelyaccelerate calcification and vice versa, calcium deposits intensely affect mechanical properties. These progressions may be synergistic, but based on comprehensive studies on the subject, is it thought that each may happen independently. It is also suggested that the geometrical design factors of the prosthetic valves are highly influential in the mechanical deterioration rate of the valve.

It should be noted that the calcification process in native aortic valves and bioprosthetic tissue valves follow dissimilar concepts. In general, the calcification process of BHVs is associated with a cascade of bioelectrochemical and bioelectromechanical events are yet to be understood. However, tissue composition and the glutaraldehyde tissue treatment seem to be two important factors. In most studiesreportedsofar, the mineral phase consists of bone-like hydroxyapatite linked with collagen and elastin, which then chemically devitalizes cells. One of the suggested methods to prevent calcification in BHVs is to remove, devitalize or extract inhabitant cells, modify the structure of collagen and elastin fibers, and add natural inhibitors.

It is well known that mechanical and biological factors contribute considerably to failure of BHVs. Even though BHVs' performance in hemodynamics and structure is excellent, they do not havesatisfactory biological factors thatare necessaryfor true biomimetic valves. Their absence of biologic properties may justify their insufficient durability after implantation. As BHVs lack living cells, unlike native valves, they are incapable of maintaining and adapting with the valvular matrix composition or maintaining an adequate calcium homeostasis. In fact, degenerative processes pushedby mechanical fatigue, proteolytic enzymes, and calcium deposition gradually deteriorate the structural components and result in progressive valve decomposition. Also, the absence of an intact layer of endothelial cells may let free influx of blood components and could also contribute to valve-related thrombogenicity. Finally, the majority of conventional BHVs, except for newer stentless models, do not uphold their cardiac skeleton-valve continuity and thus may increasingly influence heart function negatively.

BHVs gained extensive use during the mid-1970s. The major advantage of bioprosthetic valves compared to mechanical valves is that bioprosthetic valves are less prone to thromboembolic complications. Consequently, most patients receiving bioprosthetic valves do not need to take anticoagulation therapy. The main disadvantage ofbioprosthetic valves, particularly in small valve sizes, is large pressure drops (albeit their excellent hemodynamics) compared to some mechanical valvesof the same size. Complications, such as jet-like flow through the existing gaps between the valve leaflets, material fatigue and/or wear, and calcification of value cusps, particularly in children and young adults are of the issues associated with BHVs. Valve deterioration, however, typically takes place gradually in these valves. The main advantage of the conventional mechanical valves is their long-term durability. Conventional mechanical valves are manufactured from a variety of biomaterials, includingPyrolyte and Titanium. Structural failure of mechanical valves is not usual, butwhen it happens, it is catastrophic. One main disadvantage of the use of mechanical valves is the need for life-long anticoagulation therapy to lessenthe risk of thrombosis and thromboembolic complications. Since the anticoagulation therapy may result in bleeding complications, careful control of anticoagulation medication is necessaryfor the patient's well-being and quality of life.

The choice of an appropriate BHV for the patient is determined by the patient's age, since BHVs have a relatively short lifespan. There are significant differences between BHVs and MHVs. MHVs are extremely durable, but require lifelong anticoagulation therapy. They are often recommended for younger patients in order to avoid the need for a second open heart surgery or valve replacement procedure. Their use also appears to be reasonable when the patient already must take anticoagulation therapy for other medical reasons. In some cases, MHVs are preferred if the patient has a very narrow aortic basebecause their effective opening area is larger than BHVs with the same size. The risk of prosthesis endocarditis is similarly significant in the two types of prostheses.The conventionalBHVsexhibit acceptable long-term results in the aortic and mitral positions. For older patients $(65+)$, the degeneration rate of BHVsat 15 years is reported to be between $10 \%$ and $35 \%$. If a consecutive valve replacement procedure is required, the operative mortality is almost $5 \%$. The degeneration rate of $\mathrm{BHVs}$ is inversely proportional to the age of the patient at the time of implantation, so $\mathrm{BH}$ Vsare normally recommended for patients who are the age of $65+$. If a concurrent surgical procedure is necssary, such as 
Mohammadi et al. Cardiovascular System 2017,

correcting a cardiac arrhythmia by surgery during the valve replacement, this may influence the choice of BHVs for the patient. In contrast, if the patient is already taking anticoagulation therapy because of, for instance, chronic atrial fibrillation, an MHV should not necessarily be selected for the patient.

\section{The choice of a prosthetic valve in the aortic position}

The implantation of BHVs in the aortic position is desirable if the lifespan of the prosthetic is not an issue. Recent reportsindicate that the new generation of BHVsare more durable than earlier models. In addition, since the age limit is taken into consideration, re-operation rates have decreased significantly. There are the reasons that the implantation of BHVs is recommended for more elderly patients nowadays.

BHVs are known for their risk of degeneration and their need for re-operation 10-20 years after implantation; however, they are still recommended for the patients under the age of 60 . Also, in young patients who are taking oral anticoagulation therapy, BHVs are a considerable alternative. The risks involved in the second valve replacement surgery havebeen considerably reduced, which is mostly due to the advances in cardioprotection. Consequently, BHVs are recommended for younger patients; however, a second valve replacement surgery with an acceptable degree of risk may be required after $10+$ years after implantation. Also, patients who have a lower life expectancy due to chronic health issues, such as coronary heart disease, are considered for BHVs and not MHVs. The following conditions are considered for the choice of prosthetic valves in the aortic position:

- MHVs for patients who already have an MHV in their mitral or tricuspid positions

- BHVs for patients of any age who are taking oral anticoagulation therapy and for whom oral anticoagulation is unconditionally prescribed

- MHVs for patients under the age of 65 for whom oral anticoagulation is not prescribed

- BHVs for patients under the age of 65 due to a personal decision - after enough discussion with the patients about the risks of the anticoagulation therapy and the need for a second valve replacement surgery

- BHVs for patientsover the age of 65 if the risk of thromboembolism is consistently low

- A secondary valve replacement surgery with a autograft is recommended for patients with active prosthesis endocarditis

- BHVs for young female patientsif the patient is considering having childrenin future.

There are some regulations and platforms available from clinical trials for surgeons to choose the right prosthetic valve and replacement surgery. However,currently personal experience and individual assessment play a vital role in these decisions. This is often the case if the patient suffers from difficult anatomy and/or substantial comorbidity.

Ease of surgery is also important in the choice of the right valve, causing stented BHVsto bemore desirable than stentless. It should be noted thatstented BHVs' also have better long-term resultsand their implantation is associated with consistently lower risk. However, stentless valves hold certain clinical advantages, such as their excellent hemodynamic properties. The preliminary reports of 10-year studies show that stentless valves have similar deterioration, rateswhich is $\sim 20 \%$, compared to conventional stented valves. Patients with a narrow aortic base and a high risk of inconsistency between the size of the valve and aortic base may benefit from stentless valves. Also, autograft valves hold the same degeneration rates as xenografts, which has been extensively reported in long-term follow-up studies.

\section{The choice of a prosthetic valve for the mitral position and ablative surgery in atrial fibrillation}

Prosthetic valves for the mitral position are chosen based on similar same criteria as the aortic position. The rate of deterioration of the $\mathrm{BHVs}$, however, is higher in the mitral position. It is normally recommended that BHVs not be implanted in patients less than 65 years oldin the mitral position unless it is absolutely necessary. The following conditions are considered for the choice of prosthetic valves in the mitral position:

- BHVs for patients of any age who are taking oral anticoagulation therapy and for whom oral anticoagulation is unconditionally prescribed

- MHVs for patients who are under the age of 65 with longstanding atrial fibrillation

- BHVs for patients over the age of 65

- BHVs for patients under the age of 65 due to a personal decision - after enough discussion with the patients about the risks of anticoagulation therapy and the need for a second valve replacement surgery

If the patient also suffers from atrial fibrillation along with a valvular heart disease, the approach is to perform both ablative methods to attain sinus rhythm and valvular replacement during the same procedure. If the valve can be repaired or a BHV is implanted, then oral anticoagulation therapy may be stopped. It is reasonable to implant MHVs in those patients since they would require the anticoagulation therapy postoperatively regardless. Nearly $75 \%$ to $90 \%$ of patients undergoing the rhythm surgery and mitral valve replacement surgery concurrently may still be in sinus rhythm for up to six months after. The success rate of ablative surgery is known to be higher if the patient has atrial fibrillation for less than one year. Also, ablative surgery may decrease the incidence of a heart stroke. BHVs are considered an appropriate choice for those patients who cannot be permanently converted to sinus rhythm, and consequently still need the oral anticoagulation therapy. This is because if a BHV was implanted (as oppose to an MHV), a lower target INR would be required.

\section{Other Cases}

MHVs were recommended for patients associated with 
dialysis-dependent renal failure. In this situation, if $\mathrm{BHVs}$ were used, their abnormal metabolic situation couldincrease the degeneration rate. Recently, long-life studies suggest that BHVs can also be implanted for those patients as their life expectancy is already reduced.The degeneration rate due to $\mathrm{BHV}$ implantation is oftenlonger than their remaining lifetime. Since oral anticoagulation therapy is more problematic in dialysis patients than in others, MHVs are not recommended for these patients even though MHVs have longer durability. Recently, prosthetic valves were not recommended for patients with end-stage renal failure because of the risks of systemic anticoagulation.

In the case of patients that are young women desiring to have children, there is no appropriate type of prosthetic valves that can be recommended yet. In general, pregnant women with prosthetic valves are prone to heart failure, arrhythmia, or maternal endocarditis with high degree of propensity. Pregnancy decreases the life-span of BHVs significantly, and it is strongly recommended that the female patients manage their pregnancy period to be within the first five years after the implantation. It should be noted that pregnant women with MHVs hold the highest rate of maternal and fetal complications. In patients under treatment with phenprocoumone, the miscarriage rate is $\sim 70 \%$, which can be improved to $~ 20 \%$ if oral anticoagulation is replaced by heparin. The rate of chronic cardiac complications in pregnant female patients with MHVs is $\sim 20 \%$, which is almost twice as high as the rate with BHVs.

Age is a dominant factor for the choice of the best prosthetic valve. For patients over the age of 65 , it is understandable that a BHV be recommended. This is because these patients' life expectancy is decreased by comorbidity. For patients under the age of 65, MHVs are highly recommended, specifically for the mitral position. If a patient in this age group shows chronic issues to anticoagulation, then BHVs are recommended.

Patients with chronic atrial fibrillation cannot be permanently converted to a sinus rhythm by an ablative procedure. For patientswith mild arterial fibrillation, permanent oral anticoagulation therapy can be stopped by implantation of a BHValong with ablative surgery. For patients with a narrow aortic base, a stentless BHV is recommended, even though the implantation surgery is more difficult and more timeconsuming. For patients with endocarditis, mainly BHVs are proposed. For patients with prosthesis endocarditis, mainly stented or stentless MHVs are recommended.

\section{Polymeric Valves (PVs)}

Polymeric valves (PVs)are those made of flexible and synthetic biomaterials. PVs may have geometry similar to that of the native aortic heart valve. This design is a response to the unsimilar geometry of the MHVs, which are made of stiff materials (Pyrolyte) with leaflets protruding in front of the blood flow. The capacity of polymeric materials to preserve or closely simulate normal hemodynamics is because they hold a soft texture. This structure mimics the stiffness of native heart valve tissue, and easily permits contraction and expansion. This is consistent with the aortic root's movement during cardiac cycle; hence, it provides natural hemodynamics. Also, it is also likely that polymeric biomaterials can be treated to enhanceblood-compatibility. Research on prosthetic heart valves made of flexible polymers is not recent, as it has been ongoing for more than 45 years. Biomaterials tested include: silicone rubber, poly-carbonateurethane,Silastic, poly-olefin (PO), poly-tetrafluoroethylene (PTFE), SR-impregnated Dacron, and poly-urethane (PU). PU is known to have good consistency with blood, life-long durability, and thrombogenic resistance. However, calcification is a major issue with PU. Mechanical properties of the polymeric material are a significant concern in the effective formation of a polymer based prosthetic valve. In the past two decades, growing insight has been obtained into the significance of optimal hemodynamic performance of elastomeric valves for their durability. Presently, some PVs have shown their efficacy in assist devices for short-term use [93-98].

The advent of the PVs was perhaps in the late 1950's. A trileaflet PV made of silicone rubber (SR) was designed and fabricated, and then was implanted in several patients in the aortic position in 1960 and 1962. The main issue with all of these valves was thromboembolic complications. Certainly, the choice of material is a major factor in the development of PVs. Acceptable characteristics with regard to bloodcompatibility, anti-thrombogenicity, resistance to calcification and degradation, as well as excellent mechanical and material properties are significant factors for the chosen polymers to be considered for a prosthetic valve.

Silicone has great mechanical properties and is considered as a blood-compatible biomaterial. It was first used in 1960 for prosthetic valves. The issue with silicone is the formation of thrombosis and stiffening of valve leaflets, which was found in long-term clinical studies. This was enough evidence for silicone not to be considered as a blood-compatible biomaterial for PVs in 1966. Also, mechanical properties of silicone, such as low stiffness and strength, failure and short durability were other reasons against its use. Short life-span and durability was reported for silicone and poly-olefin rubbers in vivo in 1980. PVs made of PTFE or Teflon showed excellent hemodynamics properties at first. However, its low resistance to thromboembolism, calcification and leaflet thickening were the major issues with these materials, preventing them from further application in 1990.

Segmented Poly-Urethane (SPU) was introduced for PVs as an excellent biocompatible material in 1982. Medical grade SPU has been used effectively in numerous cardiovascular devices, including artificial hearts, ventricle assist devices (VAD) and blood pumps and cannulas. The trileaflet PV made of SPU, which was designed similar to the native aortic valve, showed excellent hemodynamic characteristics. It reduced turbulence and blood trauma, showedgreat flexure durability, high strength and intrinsic non-thrombogenic features. 
Mohammadi et al. Cardiovascular System 2017,

http://www.hoajonline.com/journals/pdf/2052-4358-5-2.pdf

doi: $10.7243 / 2052-4358-5-2$

PU has numerous applications in medical devicesfor a variety of purposes. Ithas multiple constructive properties due to its two-phased microstructure, which includes hard crystalline segments and soft elastomeric segments. The hard segment makes forthe structural strength, whereas the soft segment provides the flexibility and complianceto the material. PU elastomers are copolymers encompassing polyethers that are connected together by a urethane group or blocks of low molecular weight polyesters. There are 3 monomers forming these elastomers, namely an isocyanate source, which is either aromatic or aliphatic, a chain extender or curative, and a macroglycol. One application of aromatic isocyanate, which is very reactive, is methylene diphenyl diisocyanate (MDI). If a diamine chain extender is applied, typically it does not need a catalyst for synthesis. Oneapplication of an aliphatic isocyanate is the cyclo-aliphatic diisocyanate $\mathrm{H} 12 \mathrm{MDI}$, which contains polymers that change color to yellow if exposed to ultraviolet radiation and some aromatic PUs. Aromatic PUs are the polymerswhich are made of methylene dianiline (MDA), are known carcinogens and display instant cell toxicity. The hard segments are formed by the reaction of a diisocynate with a short chain diamine or diol, which are known as chain extenders. Normal extenders for medical application are 1,4 butane diol or ethylene diamine. The soft segments are formed by the reaction of the diisocynate with higher molecular weight polyols, e.g., polyesther or polycarbonate.

In recent years, notable progress has been made in polymer synthesis, which has resulted in a more bio-stable PU. A broader range of SPUs for PV leaflets is available now, such as polyester urethane, polycarbonate urethane (PCU), and polyether urethane (PEU). The issue with PEU is that it is unsuitable for long-term implants, mainly because of the hydrolytic degradation. In fact, inin vivo conditions, it is susceptible to oxidative degradation. Also, PCU holds a higher oxidative stability, and its biodegradation rate compared to PEU is considerably lower and is restricted to a thinner surface layer.

If $P U$ is chain extended with ethylene diamine (PEUE), its biostability is improved and can be used in the leaflets of PVs. This is because of its good rubbery characteristics, which improves the durability of the valve. PU can also be promoted to PCU and polyhedral oligomeric silsesquioxanes(POSS), which improves the thromboresistance property of the new nanocomposite PU polymers. In 2007, POSSPCU was shown to have decreased inflammation and capsular development in a sheep model, and no degradation was reported within 3 years after implantation. The high fibrinogen adsorption on POSSPCU and significant contact-angle hysteresis indicated that adsorbing and inactivating fibrinogen on its surface allows POSSPCU to prevent inflammation. This new composite polymer offered a better blood-compatibility and a superior biological stability than other conventional silicone based biomaterials.

The POSSPCU nanocomposite polymer has great potential for cardiovascular applications because of its excellent mechanical properties, superior surface quality and refusal to platelet adhesion. The mechanical properties of POSSPCU are comparable to that of commercially available products, e.g., Estane, Elasteon, and Chronoflex C. It was suggested to reinforce POSSPCU by adding POSS nano-particles into the polymer matrix in order to improve its tensile strength and hardness. The hydrophobic properties of the nanocomposite polymer reduce its tendency to adsorption of blood proteins, which is essential in avoiding thrombosis and calcification on the polymer surfaces.

In 2014, the author and his colleagues developed and demonstrated a novel one-piece, tricuspid valve made completely of polyvinyl alcohol cryogel reinforced by bacterial cellulose natural nanofibers (PVA-BC). The mechanical properties of the valve were effectively improved with decrease in flexural stresses of the leaflets. The stress concentrations at the commissural areas where the leaflets are connected to the stent were also avoided. However, further studies are neededto evaluate the potential of the PVA-BC valve as an effective alternative to the conventional PVs (Figure 24).

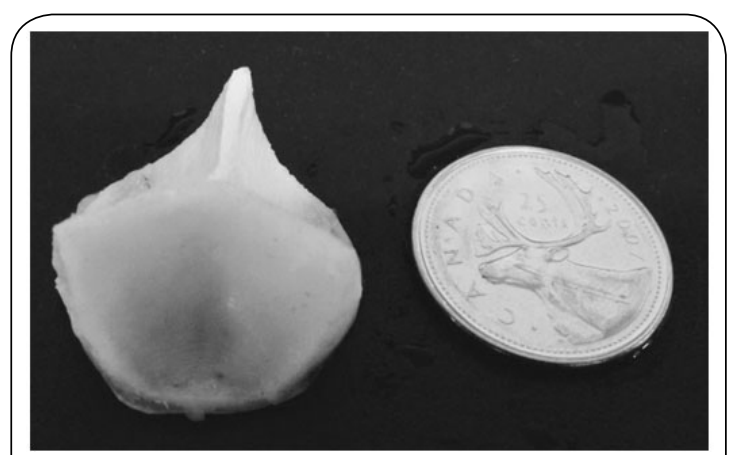

Figure 24. A one-piece, tricuspid valve made completely of polyvinyl alcohol cryogel reinforced by bacterial cellulose natural nanofibers (PVA-BC).

A polymeric MHV suitable for long-term implantation is yet to be found due to a combination of valve design and material problems. This is currently an active area in the heart valve performance laboratory at the University of British Columbia.

\section{Percutaneous Valves}

This type of valve is currently under development for older adults. It is also known as a transcatheter aortic valve,which is applied for patients with severe symptomatic aortic stenosis. Moreimportantly, it is for those who are high-risk operable candidates and are not considered suitable for traditional open heart surgery. This technology is performed on a beating heart and does not needa heart-lung machine.Percutaneous heart valve replacement or transcatheter devices are a relatively innovative technology involving the insertion of an artificial heart valve (or a device) using a catheter, rather than through the conventional open heart surgery. The portal of entry could be either via the femoral artery or vein, or 
directly through the myocardium tissue around the apical section of the heart. An expandable (or self-expandable) prosthetic heart valve is delivered and positioned at the site of the diseased native valve, which is already crushed back by an inflatable transcatheter balloon. Similar to angioplasty, a catheter is positioned in the femoral artery and then is guided into the left ventricle. Alternatively, it can be sent through the left ventricle through the apex of the heart. An inflatable balloon is then sent in place to crush the diseased valve, and then a percutaneous valve (which is compressed in a tiny tube) is placed on the balloon catheter and is guided directly inside the crushed valve. The valve's frame is inflated (or the frame opens itself if self-expandable) to secure the valve in place. This surgery is executed with general anaesthesia in a hybrid suite in which both catheterization and surgical capabilities are available. To proceed with this procedure, a team of cardiologists and imaging specialists, heart surgeons and cardiac anaesthesiologists are needed to simultaneously utilize echocardiography and fluoroscopy. The percutaneous heart valve replacement procedure is considered a quick surgery and is significantly less invasive than the conventional open heart surgery. Potential benefits of percutaneous valves are reduced recovery time and lower surgical risk. Potential drawbacks are valve migration simply because the valve is not sewn into place, issuesrelated to catheter-based delivery, and valve durability.

In available percutaneous valves, such as Edwards SAPIEN $\mathrm{XT}$, the frame (inflatable) is made of cobalt chromium and the leaflets are made of animal tissues, such as bovine pericardium. The frame could be self-expandable and made of Nitinol, such as in Medtronic CoreValve. Potential advantages of percutaneous valves include decreased recovery time and lower surgical risk. Potential disadvantages include a greater risk for valve migration (since the valve is not sewn into place), complications associated with catheter-based delivery, and uncertain valve durability. Also, similar to bioprosthetic valves, these valves are highly associated with thrombogenic complications and calcification (Figure 25).

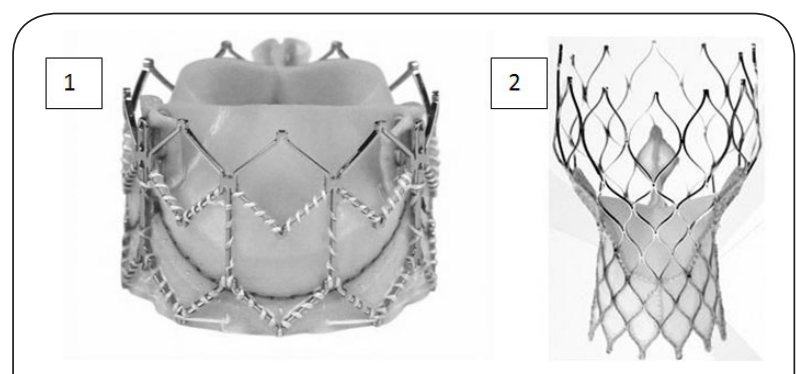

Figure 25. (1) Edwards SAPIEN XT, the frame (inflatable) which is made of cobalt chromium and the leaflets are made of animal tissues such as bovine pericardium, and (2) the frame could be self-expandable and made of Nitinol such as in Medtronic CoreValve [92].

\section{Conclusion}

In order to expand the patients' options for the implantation of BHVs, which are believed to have better performance than $M H V s$, the durability of stented BHVs should be improved. This lies in in methods of BHVs' construction and preservation. The main issue with stentless BHVs is the complications associated with the implantation process, which are not desirable by surgeons. There is a clear link between the conventional BHVs and the next generation of prosthetic valves. Also, other options such astranscatheter technologies (percutaneous valves), minimally invasive techniques, and the construction of prosthetic valves using tissue engineering seem to be promising options for the future.

\section{Competing interests}

The authors declare that they have no competing interests.

Authors' contributions

\begin{tabular}{|l|c|c|}
\hline Authors' contributions & HM & GF \\
\hline Research concept and design & $\checkmark$ & $\checkmark$ \\
\hline Collection and/or assembly of data & $\checkmark$ & -- \\
\hline Data analysis and interpretation & $\checkmark$ & $\checkmark$ \\
\hline Writing the article & $\checkmark$ & -- \\
\hline Critical revision of the article & $\checkmark$ & $\checkmark$ \\
\hline Final approval of article & $\checkmark$ & $\checkmark$ \\
\hline Statistical analysis & $\checkmark$ & $\checkmark$ \\
\hline
\end{tabular}

\section{Acknowledgement}

NSERC DG Program and the University of British Columbia for financial support.

Publication history

Senior Editor: Juan Jose Badimon, Mount Sinai School of Medicine, USA. Received: 01-May-2017 Final Revised: 14-Aug-2017

Accepted: 06-Sep-2017 Published: 21-Sep-2017

\section{References}

1. Mohammadi $\mathrm{H}$ and Mequanint K. Prosthetic aortic heart valves: modeling and design. Med Eng Phys. 2011; 33:131-47. | Article | PubMed

2. Taber, Clarence Wilbur and Venes, Donald. Taber's cyclopedic medical dictionary. F a Davis Co. 2009; 1018-23.

3. Keith L. Moore, Arthur F. Dalley and Anne M. R. Agur. "1". Clinically Oriented Anatomy. Wolters Kluwel Health/Lippincott Williams \& Wilkins. 127-73.

4. Cecie Starr, Christine Evers and Lisa Starr. Biology: Today and Tomorrow With Physiology. Cengage Learning. 2009; 422.

5. Reed, C. Roebuck, Brainerd, Lee Wherry,Lee, Rodney, Inc, the staff of Kaplan. CSET : California Subject Examinations for Teachers (3rd ed.). New York, NY: Kaplan Pub. 2008; 154.

6. “Cardiovascular diseases (CVDs) Fact sheet N³17 March 2013”. WHO. World Health Organization. Retrieved 20 September 2014.

7. I Website

8. Longo, Dan, Fauci, Anthony, Kasper, Dennis, Hauser, Stephen, Jameson, J and Loscalzo, Joseph. Harrison's Principles of Internal Medicine (18 ed.). McGraw-Hill Professional. 2011; 181.

9. “Gray's Anatomy of the Human Body - 6. Surface Markings of the Thorax". Bartleby.com. 2010-10-18. 
Mohammadi et al. Cardiovascular System 2017,

http://www.hoajonline.com/journals/pdf/2052-4358-5-2.pdf

doi: $10.7243 / 2052-4358-5-2$

10. Dorland's. Dorland's Illustrated Medical Dictionary (32nd ed.). Elsevier. 2012; 1461.

11. Bianco, Carl. "How Your Heart Works". HowStuffWorks. 2016.

12. University of Minnesota. "Papillary Muscles". Atlas of Human Cardiac Anatomy. 2016.

13. "pectinate muscle". The Free Dictionary. 2016-07-31.

14. "Main Frame Heart Development". Meddean.luc.edu. 2010-10-17.

15. DuBose T. J, Cunyus J. A and Johnson L. Embryonic Heart Rate and Age. J Diagn Med Sonography. 1990; 6:151-57.

16. DuBose TJ. Fetal Sonography. Philadelphia: WB Saunders. 1996; 263-74.

17. Terry J. DuBose Sex. Heart Rate and Age.

18. Guyton \& Hall. 2011; 110-13.

19. Website

20. Haley JP, Mohammadi $H$ and Boughner DR. The effects of hammer pressure on cellular response in a porcine heart valve tissue. Cardiovasc Eng. 2010; 10:157-62. | Article | PubMed

21. Mohammadi H, Mequanint $K$ and Bahramian F. A Galerkin-Type Finite Element Solution for the Simulation of Mass Diffusion in the Application of Tissue Engineering: Heterogeneous and Nonporous Media. Journal of Engineering in Medicine. 2010; 224:1005-1117.

22. Mohammadi $\mathrm{H}$ and Bahramian F. Boundary conditions in simulation of stenosed coronary arteries. Cardiovasc Eng. 2009; 9:83-91. | Article | PubMed

23. Mohammadi H. A numerical method to enhance the accuracy of massspring systems for modeling soft tissue deformations. J Appl Biomech. 2009; 25:271-8. I PubMed

24. Mohammadi H, Bahramian F and Wan W. Advanced modeling strategy for the analysis of heart valve leaflet tissue mechanics using high-order finite element method. Med Eng Phys. 2009; 31:1110-7. | Article | PubMed

25. Berry, William and McKenzie, Catherine. Use of inotropes in critical care. Clinical Pharmacist. 2010; 2:395.

26. Website

27. Soni, Andrew Bersten, Neil. Oh's Intensive Care Manual. (7. ed.). London: Elsevier Health Sciences. 2013; 912-22.

28. Pocock, Gillian. Human Physiology (Third ed.). Oxford University Press. 2006; 266.

29. Antz M, Otomo K, Arruda M, Scherlag BJ, Pitha J, Tondo C, Lazzara R and Jackman WM. Electrical conduction between the right atrium and the left atrium via the musculature of the coronary sinus. Circulation. 1998; 98:1790-5. | Article | PubMed

30. De PR, Ho SY, Salerno-Uriarte JA, Tritto M and Spadacini G. Electroanatomic analysis of sinus impulse propagation in normal human atria. J Cardiovasc Electrophysiol. 2002; 13:1-10. | Article | PubMed

31. "Definition of SA node". MedicineNet.com. 2012.

32. "Purkinje Fibers". About.com. 2012.

33. Guyton \& Hall. 2011; 115-20.

34. Davis J. P and Tikunova S. B. Ca2+ exchange with troponin C and cardiac muscle dynamics. Cardiovascular Research. 2008; 77:619-26.

35. "Resting pulse rate reference data for children, adolescents and adults, United States 1999-2008". 2015.

36. Hall, Arthur C. Guyton, John E. Textbook of medical physiology (11th ed.). Philadelphia: W.B. Saunders. 2005; 116-22.

37. Talley, Nicholas J and O'Connor, Simon. Clinical Examination. Churchill Livingstone. 76-82.

38. Dorland's. Dorland's Illustrated Medical Dictionary (32nd ed.). Elsevier Saunders. 2012; 1189.

39. Mohammadi $\mathrm{H}$ and Mequanint K. An Inverse Numerical Approach for Modeling Aortic Heart Valve Leaflet Tissue Oxygenation. Journal of Cardiovascular Engineering and Technology. 2011; 3:73-79

40. Newburger, Jane. Nadas' Pediatric Cardiology 2nd Edition. Philadelphia:
Elsevier. 2006; 358.

41. Robert H Anderson. The Surgical Anatomy of Aortic Root. Multimedia Manual of Cardiothoracic Surgery. 2006; 1-8.

42. Cantarini L, Lopalco G, Selmi C, Napodano S, De Rosa G, Caso F, Costa L, lannone $\mathrm{F}$ and Rigante $\mathrm{D}$. Autoimmunity and autoinflammation as the yin and yang of idiopathic recurrent acute pericarditis. Autoimmun Rev. 2015; 14:90-7. I Article | PubMed

43. Cardiovascular diseases (CVDs). World Health Organization. 2016-03-09.

44. Mohammadi $\mathrm{H}$ and Herzog W. A novel model for diffusion based release kinetics using an inverse numerical method. Med Eng Phys. 2011; 33:893-9. | Article | PubMed

45. Your Heart Failure Healthcare Team. 2016. | Website

46. Different heart diseases. World Heart Federation. 2016.

47. Britton, the editors Nicki R. Colledge, Brian R. Walker, Stuart H. Ralston and illustated by Robert. Davidson's principles and practice of medicine. (21st ed.). Edinburgh: Churchill Livingstone/Elsevier. 2010; 522-36.

48. Coven, David and Yang, Eric. Acute Coronary Syndrome Workup. Medscape. 2016.

49. William F. Armstrong, Thomas Ryan and Harvey Feigenbaum. Feigenbaum's Echocardiography. Lippincott Williams \& Wilkins. 2010.

50. Gheorghiade M, Adams KF, Jr. and Colucci WS. Digoxin in the management of cardiovascular disorders. Circulation. 2004; 109:295964. | Article | PubMed

51. Davidson's. 2010; 585-88, 614-23.

52. Anatomy of the Heart. University of Sydney Online Museum. 2016.

53. Mohammadi H. Nanocomposite biomaterial mimicking aortic heart valve leaflet mechanical behaviour. Proc Inst Mech Eng H. 2011; 225:718-22. | Article | PubMed

54. Mohammadi H., Bahramian F and Herzog W. A Finite Element Model for Simulation of Frictional Gap. Journal of Mechanical Science and Technology. 25:3099-3105

55. Mohammadi H., Bahramian F., Mequanint $K$ and Rizkalla A. A Numerical Technique to Evaluate Flexural Stiffness of Long Bones Affected by Cracks and Porosities. Journal of Mechanics in Medicine and Biology, 2011; 11:131-148.

56. Meletis J and Konstantopoulos $K$. The beliefs, myths, and reality surrounding the word hema (blood) from homer to the present. Anemia. 2010; 2010:857657. | Article | PubMed Abstract | PubMed FullText

57. Katz AM. The "modern" view of heart failure: how did we get here? Circ Heart Fail. 2008; 1:63-71. | Article | PubMed

58. Aird WC. Discovery of the cardiovascular system: from Galen to William Harvey. J Thromb Haemost. 2011; 9 Suppl 1:118-29. I Article I PubMed

59. Michelakis ED. Pulmonary arterial hypertension: yesterday, today, tomorrow. Circ Res. 2014; 115:109-14. | Article | PubMed

60. West JB. Ibn al-Nafis, the pulmonary circulation, and the Islamic Golden Age. J Appl Physiol (1985). 2008; 105:1877-80. | Article | PubMed Abstract | PubMed FullText

61. Bondke Persson A and Persson PB. Form and function in the vascular system. Acta Physiol (Oxf). 2014; 211:468-70. I Article I PubMed

62. West JB. Galen and the beginnings of Western physiology. Am J Physiol Lung Cell Mol Physiol. 2014; 307:L121-8. I Article I PubMed

63. Aird WC. Discovery of the cardiovascular system: from Galen to William Harvey. J Thromb Haemost. 2011; 9 Suppl 1:118-29. | Article | PubMed

64. Silverman ME, Grove D and Upshaw CB, Jr. Why does the heart beat? The discovery of the electrical system of the heart. Circulation. 2006 113:2775-81. | Article | PubMed

65. Cooley DA. Recollections of the early years of heart transplantation and the total artificial heart. Artif Organs. 2011; 35:353-7. | Article | PubMed

66. Miniati DN and Robbins RC. Heart transplantation: a thirty-year perspective. Annu Rev Med. 2002; 53:189-205. | Article | PubMed 
Mohammadi et al. Cardiovascular System 2017,

67. Zareh M, Fradet G, Naser B and Mohammadi H. Are Two-Dimensional Images Sufficient to Assess The Atherosclerotic Plaque Vulnerability? - A Viscoelastic and Anisotropic Finite Element Model. Journal of Cardiovascular System. 2015; 3:1-11.

68. Mohammadi H, Jahandardoost M and Fradet G. Elliptic St. Jude Bileaflet Mechanical Heart Valves. Journal of Cardiovascular System. 2015; 3:1-8.

69. Jahandardoost M, Fradet $\mathrm{G}$ and Mohammadi H. A novel computational model for the hemodynamics of bileaflet mechanical valves in the opening phase. Proc Inst Mech Eng H. 2015; 229:232-44. | Article | PubMed

70. Neubauer S. The failing heart--an engine out of fuel. N Engl J Med. 2007; 356:1140-51. | Article | PubMed

71. Website

72. "Heart". The Watkins Dictionary of Symbols.

73. Rosner Fred. Medicine in the Bible and the Talmud : selections from classical Jewish sources (Augm. ed.). Hoboken, NJ: KTAV Pub. House. 1995; 87-96.

74. Britannica Ib and Slider Ab. Egyptian heart and soul conception. The word was also transcribed by Wallis Budge asAb.

75. Allen James $P$. Middle Egyptian : an introduction to the language and culture of hieroglyphs (3rd edition. ed.). 2014; 453-465.

76. Taylor John H. Death and the afterlife in ancient Egypt. Chicago: The University of Chicago Press. 2001; 35-38.

77. Xigui Qiu and Mattos Gilbert L. Chinese writing = Wenzi-xue-gaiyao. Berkeley: Society for the Study of Early China [u.a.]. 2000; 176.

78. Rogers, Bob Flaws, Michael Johnston and Timothy. Statements of fact in traditional Chinese medicine (3rd ed.). Boulder, Colo.: Blue Poppy Press. 2007; 47.

79. Ye, Nigel Wiseman Feng. A practical dictionary of Chinese medicine (1st ed.). Brookline, Mass.: Paradigm Publications. 1998; 260.

80. Heart Valves. American Heart Association, Inc -- 10000056 Heart and Stroke Encyclopedia. American Heart Association, Inc. 2010.

81. Mendelson K and Schoen FJ. Heart valve tissue engineering: concepts, approaches, progress, and challenges. Ann Biomed Eng. 2006; 34:1799819. | Article | PubMed Abstract | PubMed FullText

82. Klabunde RE. "Pressure Gradients". Cardiovascular Physiology Concepts. Richard E. Klabunde. 2010.

83. Website

84. Website

85. Klabunde RE. Cardiac Valve Disease. Cardiovascular Physiology Concepts. Richard E. Klabunde. 2010.

86. Website

87. Anatomy photo:20:21-0102 at the SUNY Downstate Medical Center. "Heart: The Pulmonic Valve"

88. Website

89. Mohammadi H. Design and Simulation of Mechanical Heart Valve Prostheses. University of Western Ontario, London, ON, Canada. 2009.

90. Website

91. Anatomy photo:20:29-0104 at the SUNY Downstate Medical Center. "Heart: The Aortic Valve and Aortic Sinuses.

92. Website

93. Nazari S, Carli F, Salvi S, Banfi C, Aluffi A, Mourad Z, Buniva P and Rescigno $G$. Patterns of systolic stress distribution on mitral valve anterior leaflet chordal apparatus. A structural mechanical theoretical analysis. J Cardiovasc Surg (Torino). 2000; 41:193-202. | PubMed

94. Schoenwolf Gary C et al. Development of the Urogenital system". Larsen's human embryology (4th ed.). Philadelphia: Churchill Livingstone/Elsevier. 2009; 177-179.

95. Britton, the editors Nicki R. Colledge, Brian R. Walker, Stuart H. Ralston and illustrated by Robert. Davidson's principles and practice of medicine. (21st ed.). Edinburgh: Churchill Livingstone/Elsevier. 2010; 612-628.

96. Mitchell RS, Kumar V, Robbins SL, Abbas AK and Fausto N. Robbins Basic
Pathology (8th ed.). Saunders/Elsevier. 2007; 406-8.

97. Bertazzo S, Gentleman E, Cloyd KL, Chester AH, Yacoub MH and Stevens MM. Nano-analytical electron microscopy reveals fundamental insights into human cardiovascular tissue calcification. Nat Mater. 2013; 12:57683. I Article I PubMed

98. Miller JD. Cardiovascular calcification: Orbicular origins. Nat Mater. 2013; 12:476-8. | Article | PubMed

\section{Citation:}

Mohammadi H and Fradet G. Prosthetic Aortic Heart

Valves. Cardio Vasc Syst. 2017; 5:2.

http://dx.doi.org/10.7243/2052-4358-5-2 